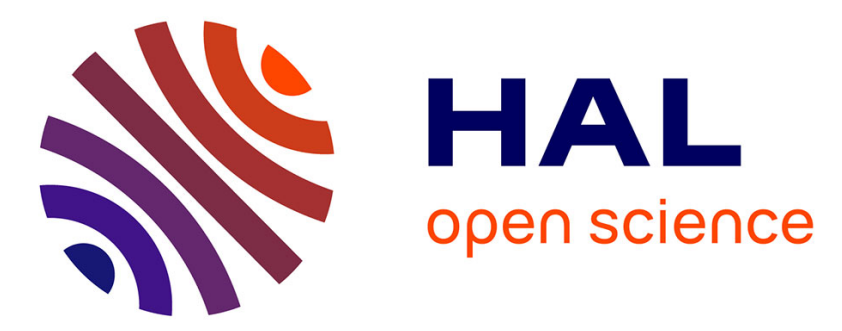

\title{
Optimal Monetary Policy and Liquidity with Heterogeneous Households
}

\author{
Florin Bilbiie, Xavier Ragot
}

\section{To cite this version:}

Florin Bilbiie, Xavier Ragot. Optimal Monetary Policy and Liquidity with Heterogeneous Households. Review of Economic Dynamics, 2021, 41, pp.71-95. 10.1016/j.red.2020.10.003 . hal-03501417

\section{HAL Id: hal-03501417 \\ https://hal-sciencespo.archives-ouvertes.fr/hal-03501417}

Submitted on 30 Dec 2021

HAL is a multi-disciplinary open access archive for the deposit and dissemination of scientific research documents, whether they are published or not. The documents may come from teaching and research institutions in France or abroad, or from public or private research centers.
L'archive ouverte pluridisciplinaire HAL, est destinée au dépôt et à la diffusion de documents scientifiques de niveau recherche, publiés ou non, émanant des établissements d'enseignement et de recherche français ou étrangers, des laboratoires publics ou privés.

\section{(이)(\$)}

Distributed under a Creative Commons Attribution - NonCommercial - NoDerivatives| 4.0 


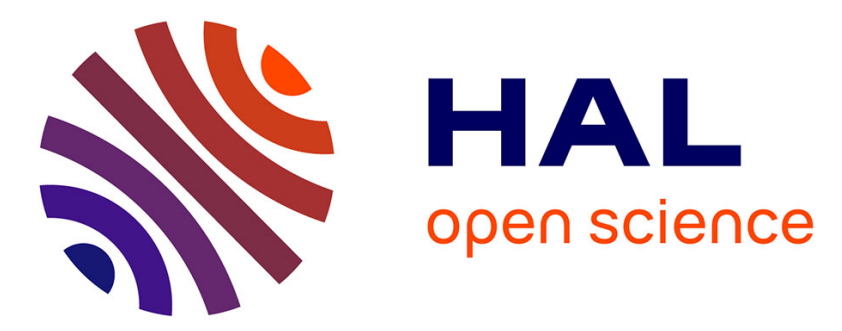

\title{
Optimal Monetary Policy and Liquidity with Heterogeneous Households
}

\author{
Florin Bilbiie, Xavier Ragot
}

\section{To cite this version:}

Florin Bilbiie, Xavier Ragot. Optimal Monetary Policy and Liquidity with Heterogeneous Households. Review of Economic Dynamics, Elsevier, 2021, 41, pp.71-95. 10.1016/j.red.2020.10.003 . hal03501417

\section{HAL Id: hal-03501417 \\ https://hal-sciencespo.archives-ouvertes.fr/hal-03501417}

Submitted on 30 Dec 2021

HAL is a multi-disciplinary open access archive for the deposit and dissemination of scientific research documents, whether they are published or not. The documents may come from teaching and research institutions in France or abroad, or from public or private research centers.
L'archive ouverte pluridisciplinaire HAL, est destinée au dépôt et à la diffusion de documents scientifiques de niveau recherche, publiés ou non, émanant des établissements d'enseignement et de recherche français ou étrangers, des laboratoires publics ou privés. 


\title{
Optimal Monetary Policy and Liquidity with Heterogeneous Households*
}

\author{
Florin O. Bilbiie ${ }^{\dagger} \quad$ Xavier Ragot ${ }^{\ddagger}$
}

December 2019

\begin{abstract}
A liquidity-insurance motive for monetary policy operates when heterogeneous households use government-provided liquidity ("money") to insure idiosyncratic risk. In our tractable sticky-price model this changes the central bank's trade-off by adding a linear benefit of insurance in the second-order approximation to aggregate welfare. Inflation volatility hinders the consumption volatility of constrained households as a side-effect of liquidity-insuring them; but price stability has significant welfare costs only when monopolistic rents are also large, what indicates a complementarity between imperfect-insurance and New-Keynesian distortions. Helicopter drops are welfare-superior to open-market operations to achieve insurance, but quantitatively their benefit is surprisingly small.
\end{abstract}

JEL Codes: D14, D31, E21, E3, E4, E5

Keywords: optimal (Ramsey) monetary policy; heterogeneous households; incomplete markets; liquidity constraints; limited participation; money; insurance, inequality; helicopter drops; open market operations.

*Previously circulated as "Monetary Policy and Inequality when Aggregate Demand Depends on Liquidity", then "Inequality, Liquidity, and Optimal Monetary Policy" and presented since March 2016. We are especially grateful to Klaus Adam, Adrien Auclert, Edouard Challe, Wei Cui, Ester Faia, Nobu Kiyotaki, Jordi Galí, Alejandro Justiniano, Eric Leeper, Francesco Lippi, Benjamin Moll, Cyril Monnet, Galo Nuno, Morten Ravn, Gilles Saint-Paul, Vincent Sterk, Paolo Surico, Andrea Tambalotti, Pierre-Olivier Weill, Mirko Wiederholt, and Michael Woodford for comments, and to numerous colleagues and participants in conferences and seminars. Bilbiie thanks (without implicating) Banque de France for financial support through the eponymous Chair at PSE, Institut Universitaire de France, and NYU and CREi for hospitality during part of writing this paper.

$\dagger$ University of Lausanne and CEPR; florin.bilbiie@gmail.com; http://florin.bilbiie.googlepages.com.

${ }^{\ddagger}$ Sciences Po, CNRS, and OFCE; xavier.ragot@gmail.com; xavier-ragot.fr 


\section{Introduction}

The aftermath of the 2008 financial crisis and the ensuing Great Recession saw an unprecedented liquidity expansion: to take one example, the year-on-year growth rate of M1 quadrupled (from 2.5 to 11 percent on average) in the post-crisis period as compared to the 2000-2008 interval. ${ }^{1}$ Among possible crisis responses, helicopter drops (HD) returned to the policy debate. ${ }^{2}$

To study optimal monetary policy in a model that can speak to these issues, we build a tractable general equilibrium New Keynesian (NK) model with heterogeneous households where aggregate demand depends on liquidity, defined as monetary assets used for self-insurance in the spirit of the seminal Bewley model. We identify a novel channel that we label the liquidity-insurance motive of optimal policy. This changes the standard stabilization objectives (of inflation and real activity) by introducing a linear term in the otherwise standard quadratic objective function of the central bank, capturing the lack of consumption insurance. Quantitatively, this implies optimal deviations from price stability in response to shocks that in standard sticky-price models generate no such trade-off. Yet we show that in a calibrated version of our model, costs of price stability are "small" even for calibrations with high enough "inequality" (imperfect insurance) implying such a linear welfare cost. However, the costs are much larger when this novel distortion co-exists with the standard NK "markup distortion", which also does not imply large deviations from price stability by itself.

It is therefore the complementarity of these two distortions that is of the essence for generating significant deviations from price stability. The reason is that the presence of monopolistic rents, what the NK literature called the "markup distortion", has distributional consequences in our framework with imperfect insurance. These considerations interact non-trivially with the liquidity-insurance motive to shape the central bank's optimal policy of liquidity provision. Despite this, the benefit of providing liquidity-insurance through direct transfers such as HD is surprisingly small compared to open-market operations (OM) for a variety of calibrated versions of our quantitative model - even though the latter means of money creation, by directing the transfer to those who do participate in financial markets, does the opposite of what is called for by the liquidity-insurance motive.

\footnotetext{
${ }^{1}$ Since nominal GDP has actually fallen during the crisis and growth thereafter does not nearly match money growth, it follows that velocity sank during the crisis and kept falling. The picture is more extreme when considering base money, whose growth rate during the three QE episodes is off the charts: above 100 percent in the crisis and its aftermath (for over a year), and around 40 percent in late 2011 and late 2013 episodes respectively. Part of this can be explained by the economy being in a liquidity trap, an aspect we abstract from here that is the focus of several other studies, e.g. Bacchetta et al (2016).

2 "Helicopter drops" were proposed by Friedman (1969), who attributes the idea to Haberler (1952), quoting: "Suppose the quantity of money is increased by tax reductions or government transfer payments, and the resulting deficit is financed by borrowing from the central bank or simply printing money". The inherent fiscal dimension is stated very clearly, as it is in Wallace (1981, p. 267): "unbacked government liabilities, liabilities that I call fiat money". Leeper (1991) and Woodford (1996) among others provide more modern treatments on fiscal-monetary interactions.
} 
In our model, heterogeneous households are subject to liquidity constraints, and liquidity is used to self-insure against uninsurable risk: financial markets are incomplete à la Bewley, and participation is limited (infrequent) in the Baumol-Tobin tradition. In equilibrium, aggregate demand depends on liquidity, which we define as the nominal asset used by households to self-insure; we call it "money", but it can be any asset whose return is affected by monetary policy. Liquidity is thus used in equilibrium as long as there is a need for insurance, or inequality, understood following the BewelyHuggett-Aiyagari (heterogeneous-agent) literature as the endogenous outcome of uninsurable shocks combined with households' ability to self-insure. We thus focus on the notion of liquidity that has a long tradition, going back at least to Friedman's (1969) analysis of the redistributive effect of monetary policy and to Bewley's (1983) formalization of that analysis.

Within the recent incomplete-market, heterogeneous-agent New Keynesian "HANK" (Kaplan, Moll, and Violante (2018)) literature, our contribution is a tractable monetary framework capturing the key insights of the Baumol-Tobin theory of money. ${ }^{3}$ The simplicity of our monetary incompletemarket NK model may be of independent interest to some researchers.

We consider - like many others - that monetary policy is the relevant tool at business cycle (quarterly) frequency to improve the distorted market outcome. Thus, we analyze the residual trade-offs for monetary policy after the (imperfect) use of any fiscal tools, without considering time-varying fiscal tools as a policy instrument. But we do let fiscal policy do much in our model: in the baseline, it takes care of the monopolistic distortion by sales subsidies, which it finances by an implicit redistribution of profit income. Indeed, liquidity is an equilibrium phenomenon because imperfect insurance subsists as fiscal policy does not undo inequality perfectly; the amount of liquidity demanded is thus an indirect metric of the lack of insurance left after fiscal policy. The degree of imperfect insurance in the model is in fact the main determinant of optimal inflation, and we calibrate it to match the (data) fall in consumption at unemployment, which takes into account any fiscal transfers. ${ }^{4}$

We study Ramsey-optimal monetary policy in this framework, and unveil a to the best of our knowledge novel channel that we call the liquidity-insurance motive, for short: with imperfect insurance (inequality) there is a rationale for providing liquidity, whose inflationary consequences' costs are generically dominated by its insurance benefits. In other words, the trade-off faced by a central bank changes: providing insurance through liquidity is consistent with its standard objectives of stabilizing inflation and aggregate demand, but our novel channel implies that inflation stabilization

\footnotetext{
${ }^{3}$ Recent microeconometric evidence supports the relationship between heterogeneity of marginal propensities to consume MPCs and liquidity constraints, e.g. Kaplan and Violante (2014), Cloyne, Ferreira, and Surico (2016).

${ }^{4}$ Note that this is the standard in monetary policy analysis: even in the baseline, textbook NK model, if the fiscal authority had enough lump-sum instruments and the ability to use them at quarterly frequency, any cost-push type shocks could be accommodated through variations in, e.g., labor-tax rates or sale subsidies - thus redistributing from firms to consumers. Similarly, the zero lower bound could be avoided by appropriate saving taxes (consumption subsidies). Standard analysis assumes that such perfect redistribution is unfeasible, which is what we also assume.
} 
take a back seat.

We illustrate this analytically by providing a second-order approximation to the aggregate welfare function à la Woodford (2003, Ch. 6). There is scope for a planner to provide consumption insurance, an objective that is costly to achieve through inflation when prices are sticky (and absent a full set of fiscal instruments). This trade-off operates in the long-run, as in any monetary model, making deflation optimal by shrinking nominal liquidity, as prescribed by the Friedman rule and its incomplete-market variants. But more importantly, and unlike other monetary sticky-price frameworks, the trade-off also operates in the short run in response to shocks: insofar as there is long-run inequality making the liquidity-insurance motive operative, optimal policy requires volatile inflation. What is more, this inflation volatility matters for welfare: a central bank that stabilizes inflation, albeit around an optimal long-run target, incurs a large welfare cost: consumers would pay (around 0.1 to 0.5 percent of consumption) to live in the economy with volatile inflation. Such deviations and welfare effects are larger than those encountered in existing monetary models with nominal rigidities.

Inflation volatility is beneficial in our economy because it dampens the consumption volatility of constrained households without much affecting the unconstrained, who can self-insure. The optimal policy consists of providing liquidity, which insures the constrained, and inflating away some of its value, in order to give the unconstrained the right intertemporal incentives to hold this liquidity for precautionary purposes.

Since the optimal policy consists of providing liquidity to insure in face of aggregate shocks, it is only natural that more direct ways of injecting this liquidity (such as helicopter drops HD) are preferable to indirect ways (such as open market operations OM). The former consist of injecting liquidity during the period so that it reaches all but especially constrained unit-MPC households. While the latter $(\mathrm{OM})$ consists of exchanging liquidity for other assets and transferring the proceeds only later through the consolidated budget, thus depriving the central bank of a within-the-period transfer. In the latter case, optimal policy thus needs to rely more on the Pigou effect, or on a distortionary tax: using (costly) inflation to influence the value of real balances of constrained households. ${ }^{5}$ We provide a rigorous welfare comparison of the two policy arrangements by calculating Ramsey-optimal policy for each and find that, for a same change in government liabilities, implementing optimal policy through HD is indeed preferable to the most favorable OM (whereby liquidity is transferred to households after one period only), but only slightly so. Thus despite there being incomplete markets and liquidity constraints of a rather extreme form, in our quantitative model the welfare benefit of implementing monetary policy through direct transfers like HD rather than open-market operations is surprisingly small.

Related Literature Our paper is at the intersection of three literatures on optimal monetary

\footnotetext{
${ }^{5}$ The two means of money creation are equivalent for welfare when prices are flexible (and inflation is like a non-distortionary tax): they just deliver different inflation and money balances paths, for a same real allocation.
} 
policy: in models with sticky prices, with money, and with heterogeneity and incomplete markets. Our model integrates two streams of monetary economics that evolved divergently over the past decades: New Keynesian (NK) models with nominal rigidities, and microfounded models of money demand with flexible prices; ${ }^{6}$ in particular, we connect two subsets focusing on heterogeneity, market incompleteness and limited participation. One stream consists of monetary theory models with limited participation and incomplete markets in the Bewley and Baumol-Tobin tradition. In our model, money is used to self-insure against idiosyncratic shocks as in Bewley models, but only for non-participating agents as in the Baumol-Tobin literature. Early key contributions with flexible prices include Bewley (1983), Scheinkman and Weiss (1986), Lucas, (1990), and Kehoe, Levine, and Woodford (1992). ${ }^{7}$ Drawing on this literature, two assumptions are key to deliver our model's tractability. First, households participating in financial markets have a high income and join a family where risk is pooled; this is an extension of Lucas (1990), also used by i.a. Challe et al. (2017) and Heathcote and Perri (2018). Second, a family head chooses the allocations of all households, including those not participating in financial markets who have a low income, under liquidity contraints. In the equilibrium that we focus on, non-participating households consume all their liquid wealth and there are only two wealth states instead of a whole distribution of wealth as in the fully-fledged Bewley model. This delivers Euler equations that preserve self-insurance through liquidity or money demand, while capturing heterogeneity in a simplified manner.

The other stream of literature that our paper is related to studies heterogeneous agents in NK models; an early, 2000s literature introduced "hand-to-mouth" consumers, or limited participation in asset markets, to study aggregate demand and monetary policy. Bilbiie (2008) is an early example of such a model focusing on monetary policy, where a subset of agents are (employed) handto-mouth and have unit MPC. ${ }^{8}$ Compared to that class of "TANK" (two-agent NK) models, we allow for temporarily-binding credit constraints and self-insurance. Quantitative HANK models also feature liquidity constraints and self-insurance in a way consistent with microeconomic heterogeneity, replicating the distributions of wealth and MPCs. Such studies of monetary policy include Kaplan

\footnotetext{
${ }^{6}$ Money demand in the NK model is generically residual when money is introduced in the utility function, through a cash-in-advance constraint, or through shopping-time distortions. This has nevertheless important consequences for optimal policy, which we review in due course.

${ }^{7}$ More recent contributions include Algan, Challe, and Ragot (2010); Alvarez and Lippi (2014); Khan and Thomas (2015); Cao et al (2016); Lippi, Ragni and Trachter (2015); Gottlieb (2015); Rocheteau, Weill and Wong (2015, 2016); and Ragot (2016).

${ }^{8}$ Galí, Lopez-Salido and Valles (2007) distinguished households according to whether they hold physical capital or not and solve the model numerically to focus on fiscal multipliers. Bilbiie (2008) derives an analytical aggregate demand Euler equation emphasizing Keynesian amplification with hand-to-mouth, and studies optimal policy. Eggertsson and Krugman (2012) combine a similar aggregate IS curve with a theory of deleveraging, debt deflation, and the liquidity trap. Nistico (2015) allows households to switch stochastically between the two states, and also computes optimal monetary policy.
} 
et al (2018), Auclert (2018), and McKay, Nakamura, and Steinsson (2016). ${ }^{9}$

Optimal policy in NK models builds on the seminal paper of Lucas and Stokey (1983), exteded to sticky prices by Khan, King, and Wollman (2003), Adao, Correia, and Teles (2003), Woodford (2003, Ch. 6), Benigno and Woodford (2005, 2012), and Schmitt-Grohe and Uribe (2004, 2007). Compared to these papers, our framework gives rise to significant optimal deviations from price stability over the cycle (i.e. not only in the long run), in response to shocks that in these standard frameworks do not generate such deviations. A welfare-maximizing central bank optimally tolerates inflation volatility due to providing liquidity for insurance (even though, as we shall see, inflation is unconditionally "bad" for constrained households because it reduces the real value of their money balances). Renouncing this volatility by adopting a policy of constant deflation at the optimal asymptotic rate has a large welfare cost in our model, whereas it is innocuous in the NK models with money demand.

Several papers study optimal monetary policy with heterogeneous households and sticky prices. Bilbiie (2008) derived optimal policy in a TANK model, where a fraction of households are hand-to-mouth; Curdia and Woodford (2009) and Nistico (2016) do the same in models with infrequent participation and borrowers and savers. The setup of these last two papers shares similarities to ours, in particular concerning the "infrequent participation" structure that draws on an earlier monetary theory literature; but in the domain of optimal policy, these studies focus on the case where there is perfect insurance in steady state, thus abstracting from the liquidity-insurance, or inequality channel that gives rise to the novel trade-off we emphasize.

Several more recent and independent papers deal broadly with the same topic but differ substantially and in several key respects: assumptions about the environment, solution techniques, results, and economic intuition and mechanisms. Differently from Bhandari, Evans, Golosov and Sargent (2018), we consider an economy with two assets to analyze the role of liquidity injections when liquidity constraints bind occasionally; this is also different relative to Challe (2019) and Nuno and Thomas (2018). The key mechanism we focus on is self-insurance through liquidity in an economy with two types of assets liquid and illiquid, and limited participation. In both Bhandari et al and Nuno and Thomas a main channel, absent in our paper, is instead "Fisherian": inflation redistributes from savers to borrowers by reducing the value of debt. In Challe's model with uninsurable idiosyncratic risk given by endogenous unemployment (but no equilibrium trade and no endogenous liquidity), there are no deviations from price stability under optimal policy.

What distinguishes our framework is the introduction of limited participation in financial markets

\footnotetext{
${ }^{9}$ See also i.a. Guerrieri and Lorenzoni (2017), Gornemann, Kuester, and Nakajima (2018), Ravn and Sterk (2018), Den Haan, Rendhal and Riegler (2016), McKay and Reis (2015), Hagedorn, Luo, Manovskii, and Mitman (2019), Debortoli and Gali (2018). Bilbiie (2018, 2019) emphasizes the role of cyclical inequality for a wide range of monetary and fiscal policy issues with heterogeneity in an analytical model.
} 
as a microfoundation for liquidity-money. We focus on and isolate a novel trade-off between liquidityinsurance and standard stabilization, illustrated through a "loss function". The Ramsey problem that we solve is simple and transparent and implies that imperfect long-run consumption insurance is essential (in conjunction with the presence of monopolistic rents, which also have a distributional dimension) to motivate large optimal deviations from price stability. We also conduct a meaningful welfare comparison of $\mathrm{HD}$ and $\mathrm{OM}$ as ways to provide liquidity.

Lastly, this paper is complementary to our own related independent work. Bilbiie (2017, 2018) builds a tractable-HANK model with liquid bonds and illiquid stocks and uses it as a reduced projection of key summary statistics of rich HANK models, disentangling between inequality and risk, and analyzes monetary and fiscal policy transmission transmission, multipliers, and forward guidance -including in liquidity traps; the latter paper derives optimal monetary poliy in a cashless model where the reasons to deviate from price stability analyzed here are absent altogether. Legrand and Ragot (2018) use a flexible-price, one asset model to derive a general method (using the "history space") for calculating Ramsey fiscal policy in heterogeneous-agent models. A companion note Bilbiie and Ragot (2019) analyzes the effect of liquidity-inducing helicopter drops on aggregate demand and inequality.

\section{A Monetary NK Model with Heterogeneous Households}

We build a simple, tractable, heterogeneous-agent, New Keynesian model with money: heterogenous households hold money to self-insure against idiosyncratic risk, markets are incomplete, participation is limited (infrequent), and price adjustment is costly. The main idea, following contributions reviewed in the introduction and referred to below, is to introduce partial insurance among a subgroup of households to reduce heterogeneity while preserving the self-insurance motive. The model can be understood as an extension of Lucas (1990) to generate a relevant increase in heterogeneity across agents. Following Lucas, we stick to the family metaphor to ease the presentation.

Households. There is a mass 1 of households, indexed by $j \in[0,1]$, who discount the future at rate $\beta$ and derive utility from consumption $c_{t}^{j}$ and disutility from labor supply $l_{t}^{j}$. The period utility function is:

$$
u\left(c_{t}^{j}\right)-\chi \frac{\left(l_{t}^{j}\right)^{1+\varphi}}{1+\varphi},
$$

with $u(c)=\left(c^{1-\gamma}-1\right) /(1-\gamma)$. Households have access to three assets: money (with zero nominal return), public debt (with nominal return $i_{t}>0$ ), and shares in monopolistically competitive firms. Money is held despite being a dominated asset because financial frictions give it a consumptionsmoothing, insurance role. These frictions are: uninsurable idiosyncratic risks and infrequent participation in financial markets. Such frictions customarily generate a large amount of heterogeneity: 
the economy is characterized by a continuous distribution of wealth, which is very hard to study with aggregate shocks and sticky prices.

To simplify the problem (and thus enable us to perform the analysis previewed in the Introduction), we use tools developed in the incomplete-markets literature to reduce the amount of heterogeneity. These simplifications keep the essence of intertemporal trade-offs and of redistributive effects of monetary policy in general equilibrium, and can be viewed as a simple generalization of the Lucas (1990) multiple-member household metaphor. As we shall see, in our economy the key intertemporal trade-offs are captured by households' Euler equations for money and other assets; at the same time, a relevant but limited amount of heterogeneity captures the redistributive effects of inflation and money creation. The gain of this modeling strategy is that one can use standard techniques used in representative-agent (New Keynesian or otherwise) models. In particular, we can compute Ramsey-optimal policy with aggregate shocks.

Households participate infrequently in financial markets. When they do, they can freely adjust their portfolio and receive dividends from firms. When they do not, they can use only money to smooth consumption. Denote by $\alpha$ the probability to keep participating in period $t+1$, conditional upon participating at $t$ (hence, the probability to switch to not participating is $1-\alpha$ ). Likewise, call $\rho$ the probability to keep non-participating in period $t+1$, conditional upon not participating at $t$ (hence, the probability to become a participant is $1-\rho$ ). The fraction of participating households is $n=(1-\rho) /(2-\alpha-\rho)$, and the fraction $1-n=(1-\alpha) /(2-\alpha-\rho)$ does not participate.

Furthermore, households belong to a family whose head maximizes the intertemporal welfare of family members using a utilitarian welfare criterion (all households are equally weighted), but faces some limits to the amount of risk sharing that it can do. Households can be thought of as being in two states or "islands"10. All households who are participating in financial markets are on the same island, called $P$. All households who are not participating in financial markets are on the same island, called $N$. The family head can transfer all resources across households within the island, but cannot transfer some resources between islands.

Households in the participating island work at real wage $w_{t}$. To simplify the exposition, we assume as a benchmark that non-participating households work to get a fixed exogenous income, a home-production amount $\delta$ (which is also their fixed labor supply) that is low enough to induce them to self-insure. This isolates the channel that we want to emphasize: self-insurance through money in face of uninsurable risk. In this version, a natural interpretation of the idiosyncratic risk is related to unemployment, but our framework is more general and can accommodate several others: broadly speaking, we can think of these shocks as "liquidity shocks", i.e. any shock that makes households

\footnotetext{
${ }^{10}$ The use of the family head and island metaphors builds on Challe et al (2017); this is generalized further, in diferent directions, by Legrand and Ragot (2018) and Bilbiie (2018). Se also Heathcote and Perri (2018) for a different simplifying family structure.
} 
want to consume and increase their demand for liquidity. We then relax this assumption and study a version of the model where non-participating households also work at the market wage.

The timing is the following. At the beginning of the period, the family head pools resources within the island. The aggregate shocks are revealed and the family head determines the consumption/saving choice for each household in each island. Then households learn their next-period participation status and have to move to the corresponding island accordingly, taking only money with them. The key assumption is that the family head cannot make transfers to households after the idiosyncratic shock is revealed, and will take this as a constraint for the consumption/saving choice.

The flows across islands are as follows. The total measure of households leaving the $N$ island each period is the number of households who participate next period: $(1-n)(1-\rho)$. The measure of households staying on the island is thus $(1-n) \rho$. In addition, a measure $(1-\alpha) n$ leaves the $P$ island for the $N$ island at the end of each period.

Total welfare maximization implies that the family head pools resources at the beginning of the period in a given island and implements symmetric consumption/saving choices for all households in that island. Denote as $b_{t+1}^{P}$ and $M_{t+1}^{P}$ the per-capita period $t$ bonds and money balances respectively, in the $P$ island, after the consumption-saving choice. The real money balances are $m_{t+1}^{P}=M_{t+1}^{P} / \mathcal{P}_{t}$, where $\mathcal{P}_{t}$ is the price level. The end-of-period per capita real values (after the consumption/saving choice but before agents move across islands) are $\tilde{b}_{t+1}^{P}$ and $\tilde{m}_{t+1}^{P}$. Denote as $m_{t}^{N}$ the per capita beginning-of-period capital money in the $N$ island (where the only asset is money). The end-ofperiod values (before agents move across islands) are $\tilde{m}_{t+1}^{N}$. We have the following relations (as bonds do not leave the $P$ island, we have $\left.b_{t+1}^{P}=\tilde{b}_{t+1}^{P}\right)$ :

$$
\begin{aligned}
& m_{t+1}^{P}=\alpha \tilde{m}_{t+1}^{P}+(1-\alpha) \tilde{m}_{t+1}^{N} \\
& m_{t+1}^{N}=(1-\rho) \tilde{m}_{t+1}^{P}+\rho \tilde{m}_{t+1}^{N} .
\end{aligned}
$$

The program of the family head is (with $\pi_{t}=\left(\mathcal{P}_{t}-\mathcal{P}_{t-1}\right) / \mathcal{P}_{t-1}$ denoting the net inflation rate):

$$
\begin{aligned}
W\left(b_{t}^{P}, m_{t}^{P}, m_{t}^{N}, X_{t}\right)= & \max _{\substack{\left\{c_{t}^{P}, \tilde{b}_{t+1}^{P}, \tilde{m}_{t+1}^{P}, \tilde{m}_{t+1}^{N}, c_{t}^{N}, l_{t}^{P}\right\}}} n\left[u\left(c_{t}^{P}\right)-\chi \frac{\left(l_{t}^{P}\right)^{1+\varphi}}{1+\varphi}\right]+(1-n)\left[u\left(c_{t}^{N}\right)-\chi \frac{\delta^{1+\varphi}}{1+\varphi}\right] \\
& +\beta E W\left(b_{t+1}^{P}, m_{t+1}^{P}, m_{t+1}^{N}, X_{t+1}\right)
\end{aligned}
$$

subject to:

$$
\begin{aligned}
c_{t}^{P}+\tilde{b}_{t+1}^{P}+\tilde{m}_{t+1}^{P} & =w_{t} l_{t}^{P}-\tau_{t}^{P} \\
& +\frac{1+i_{t-1}}{1+\pi_{t}} b_{t}^{P}+\frac{m_{t}^{P}}{1+\pi_{t}}+\frac{1}{n} d_{t}, \\
\tilde{m}_{t+1}^{N}+c_{t}^{N} & =\delta-\tau_{t}^{N}+\frac{m_{t}^{N}}{1+\pi_{t}} \\
\tilde{m}_{t+1}^{P}, \tilde{m}_{t+1}^{N} & \geq 0
\end{aligned}
$$


and the laws of motion for money flows relating $m_{t+1}^{j}$ to $\tilde{m}_{t+1}^{j}(1)$. Equation (2) is the per capita budget constraint in the $P$ island: $P$-households (who own all the firms) receive dividends $d_{t} / n$, and the real return on money and bond holdings. With these resources they consume and save in money in bonds, and pay taxes/receive transfers $\tau_{t}^{P}$ (lump-sum taxes include any new money created or destroyed). Equation (3) is the budget constraint in the $N$ island. Finally (4) are positive constraints on money holdings and are akin to credit constraints in the heterogeneous-agent literature. The variable $X_{t}$ in the value function refers to all relevant period $t$ information necessary to form rational expectations. Using the first-order and envelope conditions, we have:

$$
\begin{aligned}
u^{\prime}\left(c_{t}^{P}\right) & \geq \beta E \frac{1+i_{t}}{1+\pi_{t+1}} u^{\prime}\left(c_{t+1}^{P}\right) \text { and } \tilde{b}_{t+1}^{P}=0 \\
u^{\prime}\left(c_{t}^{P}\right) & \geq \beta E\left[\alpha u^{\prime}\left(c_{t+1}^{P}\right)+(1-\alpha) u^{\prime}\left(c_{t+1}^{N}\right)\right] \frac{1}{1+\pi_{t+1}} \text { or } \tilde{m}_{t+1}^{P}=0 \\
u^{\prime}\left(c_{t}^{N}\right) & \geq \beta E\left[(1-\rho) u^{\prime}\left(c_{t+1}^{P}\right)+\rho u^{\prime}\left(c_{t+1}^{N}\right)\right] \frac{1}{1+\pi_{t+1}} \text { or } \tilde{m}_{t+1}^{N}=0 \\
w_{t} u^{\prime}\left(c_{t}^{P}\right) & =\chi\left(l_{t}^{P}\right)^{\varphi}
\end{aligned}
$$

The first Euler equation corresponds to the choice of bonds: there is no self-insurance motive, for they cannot be carried to the $N$ island: the equation is the same as with a representative agent. ${ }^{11}$

The money choice of $P$-island agents is governed by (6), which takes into account that money can be used when moving to the $N$ island. The third equation (7) determines the money choice of agents in the $N$ island, and the last equation labor supply.

The important implication of this market structure is that the Euler equations (6) and (7) have the same form as in a fully-fledged incomplete-markets model of the Bewely-Huggett-Aiyagari type. In particular, the probability $1-\alpha$ measures the uninsurable risk to switch to "low income" (unemployment) next period, risk for which money is the only means to self-insure. This is why money is held in equilibrium for self-insurance purposes, despite being a dominated asset.

Production and Price Setting. The final good is produced by a firm using intermediate goods as inputs. The final sector production function is $Y_{t}=\left(\int_{0}^{1}\left(y_{t}(z)\right)^{1-\frac{1}{\varepsilon}} d z\right)^{\frac{\varepsilon}{\varepsilon-1}}$, where $y_{t}$ is the amount of intermediate good $z$ used in production. Denote as $\mathcal{P}_{t}(z)$ the price of intermediate goods $z$. Demand for an individual product is $Y_{t}(z)=\left(\mathcal{P}_{t}(z) / \mathcal{P}_{t}\right)^{-\varepsilon} Y_{t}$ with the welfare-based price index $\mathcal{P}_{t}=\left(\int_{0}^{1} \mathcal{P}_{t}(z)^{1-\varepsilon} d z\right)^{\frac{1}{1-\varepsilon}}$. Each individual good is produced by a monopolistic competitive firm, indexed by $z$, using a technology given by: $Y_{t}(z)=A_{t} l_{t}(z)$. Cost minimization, taking the wage as given, implies that the real marginal cost is $W_{t} /\left(A_{t} \mathcal{P}_{t}\right)$. The problem of producer $z$ is to

\footnotetext{
${ }^{11}$ An intuition for the underlying market structure is as follows. As agents pool resources when participating (which would be optimal with symmetric agents in time 0 and time 0 trading), they perceive a return conditional on participating next period in financial markets. This exactly compensates for the probability of not participating next period, thus generating the same Euler equation as with a representative agent.
} 
maximize the present value of future profits, discounted using the stochastic discount factor of their shareholders, the participants.

When price adjustment is frictionless, prices of all firms are equal to a constant markup over the nominal marginal cost - the real marginal cost is constant $W_{t} /\left(A_{t} \mathcal{P}_{t}\right)=(\varepsilon-1) / \varepsilon$. We assume that firms are subject to nominal rigidities as in Rotemberg (1982): to change their prices, firms incur a quadratic adjustment cost that is homogenous across firms. Profits of each firm are thus given by $d_{t}=\left(1-\frac{w_{t}}{A_{t}}-\frac{\nu}{2} \pi_{t}^{2}\right) Y_{t}$, anticipating that the equilibrium is symmetric. Maximization of their present discounted value gives rise to the nonlinear forward-looking "New Keynesian Phillips curve", whose derivation is described in detail in the Appendix - where we replaced the labor supply schedule $w_{t}=\chi\left(l_{t}^{P}\right)^{\varphi}\left(c_{t}^{P}\right)^{\gamma}$ :

$$
\pi_{t}\left(1+\pi_{t}\right)=\beta E_{t}\left[\left(\frac{c_{t}^{P}}{c_{t+1}^{P}}\right)^{\gamma} \frac{Y_{t+1}}{Y_{t}} \pi_{t+1}\left(1+\pi_{t+1}\right)\right]+\frac{\varepsilon}{\nu}\left(\frac{\chi\left(l_{t}^{P}\right)^{\varphi}\left(c_{t}^{P}\right)^{\gamma}}{A_{t}}+\Phi-1\right)
$$

where $\Phi \equiv 1-(\varepsilon-1)(1+\sigma) / \varepsilon$ captures the steady-state distortion and $\sigma$ is a corrective sales subsidy. In particular, when the subsidy is equal to the desired net markup $\sigma=(\varepsilon-1)^{-1}$, there is no steady-state distortion associated with monopolistic competition and elastic labor, $\Phi=0$. These considerations will be useful when studying the Ramsey policy below.

Money Creation and the Government Budget. To start with, we assume that money is created through "helicopter drops", although we also look at the implications of open-market operations later. Furthermore, we focus on uniform taxation $\tau_{t}^{P}=\tau_{t}^{N}=\tau_{t}{ }^{12}$. Denote by $x_{t}$ the (real value of) new money created in period $t$, and by $M_{t+1}^{t o t}$ the total nominal quantity of money in circulation at the end of each period. In nominal terms, $M_{t+1}^{t o t}=M_{t}^{t o t}+\mathcal{P}_{t} x_{t}$, and in real terms:

$$
m_{t+1}^{t o t}=\frac{m_{t}^{t o t}}{1+\pi_{t}}+x_{t}
$$

Hence, the total period $t$ net taxes/transfers are $\tau_{t}=-x_{t}$.

Market clearing and equilibrium. Since there is no public debt, the period $t$ market for bonds is $n b_{t+1}^{p}=0$. The money market clears $m_{t+1}^{t o t}=(1-n) \tilde{m}_{t+1}^{N}+n \tilde{m}_{t+1}^{P}$ and so does the labor market $l_{t}=n l_{t}^{P}$. Denoting by $c_{t}$ total consumption and $Y_{t}=A_{t} l_{t}$ market-produced output (or earned total income), we have that the goods market will also clear, by Walras' Law:

$$
c_{t} \equiv n c_{t}^{P}+(1-n) c_{t}^{N}=\left(1-\frac{\nu}{2} \pi_{t}^{2}\right) Y_{t}+(1-n) \delta
$$

\footnotetext{
${ }^{12}$ We could introduce a more general fiscal system by choosing type-specific transfers: $\tau_{t}^{P}=\frac{\omega}{n} \tau_{t} ; \tau_{t}^{N}=$ $\frac{1-\omega}{1-n} \tau_{t}$ where $\omega$ is the share of total taxes paid by all type-N agents (we focus here on $\omega=n$, entirely lump-sum transfers). In particular, it can be easily shown that there exist (i) processes $\tau_{t}^{j}$ that (redistribute money so as to) replicate Woodford's cashless limit; and (ii) a value of $\omega$ that restores neutrality and Wallace's 1981 logic - i.e. "keeping fiscal policy constant" in the sense of finding an (exogenous) redistribution that un-does the endogenous redistribution triggered by a monetary policy shock in our framework.
} 
Note for further use that there is a resource cost of changing prices (inflation), which is isomorphic to the welfare cost of relative price dispersion in a Calvo-type model, see e.g. Woodford (2003). In Appendix A we provide the summary of model equations and the equilibrium definition.

Steady state. The analysis of the model's steady state (defined as an allocation where real variables are constant and nominal variables grow at a constant rate $\pi$ ) provides a series of first insights into its monetary structure. The Euler equation for bonds implies that their real return is always equal to the inverse of the discount factor:

$$
\frac{1+i}{1+\pi}=\beta^{-1}
$$

Defining $q_{t} \equiv c_{t}^{P} / c_{t}^{N}$, as consumption inequality (imperfect insurance), the self-insurance Euler equation delivers:

$$
q \equiv \frac{c^{P}}{c^{N}}=\left(\frac{\frac{1+\pi}{\beta}-\alpha}{1-\alpha}\right)^{\frac{1}{\gamma}}>1 .
$$

Letting the steady-state share of exogenous income of $\mathrm{N}$ in average consumption be $\delta_{c} \equiv \delta / c$, where $c=n c^{P}+(1-n) c^{N}$ (recall this is home production, or unemployment benefits when interpreting idiosyncratic risk as unemployment risk), and the share of $N$ households' consumption in total be $h$ (with the share of P's consumption in total similarly denoted by $p$ ):

$$
h \equiv \frac{c^{N}}{c}=\frac{1}{1+n(q-1)},
$$

we find (as long as it is positive) the steady-state money demand share, or inverse consumption velocity of money: ${ }^{13}$

$$
\mu \equiv \frac{m^{t o t}}{c}=\frac{\left(h-\delta_{c}\right)(1+\pi)}{2-\rho-\alpha+\pi} .
$$

Subject to a caveat of existence of a monetary equilibrium, discussed in detail in Appendix A , steady-state money demand is equal to the share of (non-home-produced) consumption of $\mathrm{N}$ (adjusted for inflation), divided by a parameter capturing the degree of overall churning, the sum of the transition probabilities from one state to another. Under the restriction $\alpha+\rho>1$ (which we return to below), this parameter is between 0 and 1. For a given level of home production, this expression implicitly defines upper bounds on the degree of market incompleteness (as described by $\alpha$ and $\rho$ ) so that steady-state money demand is positive. ${ }^{14}$ Conversely, for given $\alpha$ and $\rho$ there exists a threshold $\bar{\delta}$ beyond which $P$ choose not to hold money: the outside option is too good and there is no need to self-insure. Thus, $\delta_{c}$ captures the degree of insurance provided by (un-modelled) fiscal transfers: were it high enough, no liquidity would be traded $\mu=0$ and there would be no role for

\footnotetext{
${ }^{13}$ Appendix B.6 provides the expression for the model variant where $N$ are employed at the market wage.

${ }^{14}$ The formal restriction is, for the case of zero steady-state inflation and treating $n$ as a parameter: $\alpha<1-n \frac{\beta^{-1}-1}{\delta_{c}^{-1}-1}<$ $\beta^{-1}$. In terms of the original parameter $\rho$ we have $\frac{1-\alpha}{1-\rho}>\sqrt{\frac{1}{4}+\frac{(1-\beta) \delta_{c}}{(1-\rho) \beta\left(1-\delta_{c}\right)}}-\frac{1}{2}$.
} 
monetary policy in this model beyond its standard role in cashless models [XR I give a name to the threshold because it is not cealr that $\bar{\delta}=h$, as we don't discuss it]. We will focus on the case with equilibrium liquidity and inequality, $\delta_{c}<\bar{\delta}<1$. In Appendix A, we show that this implies that $\mathrm{N}$ households choose not to hold money at the end the period. Hence, $\tilde{m}_{t+1}^{N}=0$, what simplies further the algebra.

Our concept of liquidity, whereby bonds and equity are illiquid while money is liquid, follows the monetary theory that we reviewed above. For the baseline version of our model only, and in order to isolate the role of liquidity-insurance, we also assumed that constrained households have exogenous income. Yet an earlier literature already discussed at length the amplifying, Keynesian effect on monetary transmission with hand-to-mouth households who have endogenous income because they are employed (see Bilbiie 2008, 2018, 2019 and the discussion in the Introduction). We first abstract from that well-understood general equilibrium channel to isolate and better understand another, which we emphasize below - endogenous movements in liquidity. We then introduce this channel too by assuming that constrained households are employed and have endogenous income, in Section 4.2 and Apendix B.6.

\section{Optimal Monetary Policy: Insurance, Liquidity, and In- flation}

To understand the role of inflation for redistribution and providing insurance, it is useful to start by looking at the first-best benchmark (the planner solution) and compare it to our economy with flexible prices. The first best allocation is obtained when the planner chooses quantities to maximize ex-ante aggregate welfare:

$$
\max _{c_{t}^{P} c_{t}^{N}, l_{t}^{P}} E_{0} \sum_{t=0}^{\infty} \beta^{t}\left(n\left[u\left(c_{t}^{P}\right)-\chi \frac{\left(l_{t}^{P}\right)^{1+\varphi}}{1+\varphi}\right]+(1-n)\left[u\left(c_{t}^{N}\right)-\chi \frac{\delta^{1+\varphi}}{1+\varphi}\right]\right)
$$

subject to the resource constraint $n c_{t}^{P}+(1-n) c_{t}^{N}=n A_{t} l_{t}^{P}+(1-n) \delta$. Effectively, there is no intertemporal problem: the first-best equilibrium is one with perfect insurance, given by the two conditions $c_{t}^{P}=c_{t}^{N}=c_{t}$ and $c_{t}=\chi^{-1 / \gamma}\left(l_{t}^{P}\right)^{-\varphi / \gamma} A_{t}^{1 / \gamma}$.

Flexible prices. [XR : I add title because it was not clear when we swith from felxible to sticky prices] Consider now the market economy with flexible prices, $\nu=0$. The firstbest allocation can be implemented at the Friedman rule, i.e. when the nominal interest rate is $i=0$, and the inflation rate $\pi=\beta-1$ (because the real interest rate is $\beta$ ): the return on money is equal to the real interest rate and there is no opportunity cost to self-insure. But our framework exhibits a difficulty which is well known in this class of monetary models starting from Bewley (1983): that, at the Friedman rule, monetary variables are indeterminate - whatever the nominal quantity of money, 
the price of the final good is indeterminate when the real quantity of money allows households to self-insure; ${ }^{15}$ furthermore, there exist examples of Bewley economies in which the Friedman rule is not optimal because of a redistribution effect, e.g. when interest is paid through lump-sum taxes, see Mehrling (1995). The full analysis of this case is provided in Appendix B.2.

Stick prices. Inspecting the budget constraint of constraint agents (3), having imposed assetmarket clearing and money creation:

$$
c_{t}^{N}=\delta-x_{t}+\frac{1-\alpha}{1-n} \frac{m_{t}^{t o t}}{1+\pi_{t}},
$$

illustrates transparently why a trade-off occurs with sticky prices $(\nu>0)$.

Issuing liquidity to insure constrained agents $x_{t}$, as required by optimality, will in general be inflationary. Inflation erodes the oustanding real balances of the constrained via the Pigou effect. But more importantly, inflation fluctuations generated by liquidity movements that allow households to self-insure also generate price adjustment costs. A zero-inflation policy minimizes these price adjustment costs, but decrease the ability of households to self-insure. Optimal monetary policy needs to find the balance between these two distortions: inequality, or a scope for providing liquidityinsurance (specific to an incomplete-markets, limited-participation setup like ours), and costly price adjustment: the standard distortion that operates in a representative-agent NK model. This section analyzes how this trade-off is resolved in our model. We solve the full Ramsey-optimal policy, provide a second-order approximation à la Woodford (2003) that is useful to understand the policy trade-offs, and analyze optimal policy quantitatively. To foreshadow our main result, inequality (understood as imperfect insurance) triggers a liquidity-insurance motive that, in conjunction with the presence of monopolistic rents, implies large optimal deviations from price stability in response to shocks that, absent liquidity, are innocuous.

\subsection{Ramsey-Optimal Policy}

Following a long tradition started by Lucas and Stokey (1983), we assume that the central bank acts as a Ramsey planner who maximizes aggregate welfare. In our economy, this entails calculating the welfare of the two agents and weighting them by their shares in the population. The constraints of the planner are the rearranged private equilibrium conditions: the relevant self-insurance condition (6), the Phillips curve (9), and the economy resource constraint (11). ${ }^{16}$ We denote the system of

\footnotetext{
${ }^{15}$ This indeterminacy is also found in cash-in-advance or money-in-the-utility models with no satiation point, see e.g. Correia and Teles (1999). In our model, this is not a too serious critique of the Friedman Rule: we show in the Appendix that when the policy rule converges to it $i \longrightarrow 0^{+}$the allocation is well-defined and converges smoothly to the first-best allocation.

${ }^{16}$ Since the nominal interest rate enters only the Euler equation for bonds, the problem can be regarded as one where the planner chooses the allocation directly; once the consumption of participants and inflation are known, the optimal
} 
these three constraints by $\Gamma_{t}\left(c_{t}^{P}, c_{t}^{N}, l_{t}^{P}, \pi_{t}\right)$. As it is by now well understood, the optimal policy problem of the central bank can be written as choosing the allocation $\left\{c_{t}^{P}, c_{t}^{N}, l_{t}^{P}, \pi_{t}\right\}$ to maximize the following Lagrangian:

$$
\max _{\left\{c_{t}^{P}, c_{t}^{N}, l_{t}^{P}, \pi_{t}\right\}} E_{0} \sum_{t=0}^{\infty} \beta^{t}\left\{n\left[u\left(c_{t}^{P}\right)-\chi \frac{\left(l_{t}^{P}\right)^{1+\varphi}}{1+\varphi}\right]+(1-n)\left[u\left(c_{t}^{N}\right)-\chi \frac{\delta^{1+\varphi}}{1+\varphi}\right]+\omega_{t} \Gamma_{t}\right\}
$$

where $\omega_{t}$ is the vector of three costate, Lagrange multipliers, one for each constraint in $\Gamma_{t}$. The first-order conditions of this problem are outlined in Appendix B.3, as is the proof of the following Proposition.

Proposition 1 The optimal long-run inflation rate is such that $\beta-1 \leq \pi^{*} \leq 0$.

As in other NK models incorporating different theories of money demand (e.g. Khan et al, 2003; Schmitt-Grohe and Uribe, 2004, 2007), the long-run inflation rate ranges from the Friedman rule under flexible prices and optimal subsidy, to zero inflation under sticky prices and inelastic labor. A low inflation rate allows households to self-insure, but generates price adjustment costs. An inflation rate close to 0 minimizes price adjustment costs, but decreases the ability of households to self-insure, as the return on money decreases.

But unlike in other NK models, including those incorporating money demand, in our economy the central bank also uses inflation optimally over the cycle, as a by-product of using liquidity to provide insurance and decrease inequality. We first illustrate formally the trade-off faced by a central bank by deriving a second-order approximation to the aggregate utility function, which contains a liquidity-insurance motive, and we then explore the quantitative significance of this novel trade-off.

\subsection{Insurance vs Stabilization: A Second-order Welfare Approximation}

To understand the relevant policy trade-offs, we derive a second-order approximation à la Woodford (2003, Ch. 6) to the aggregate welfare function, around a steady-state with imperfect insurance $(p>1>h)$, an optimal subsidy inducing marginal-cost pricing in steady state $(\Phi=0$ in $(9))$, and arbitrary steady-state inflation. ${ }^{17}$ Appendix B.5 presents the proof of this Proposition.

interest rate is determined by the Euler equation. By similar reasoning, once the consumption of non-participants is determined, along with inflation, the quantity of real money balances is fully determined too. These simplifications apply only when money is issued via helicopter drops; see Appendix B.4 [XR the link was not the good one] for the case of optimal policy under open-market operations.

${ }^{17}$ Bilbiie (2008, 2019), Curdia and Woodford (2016), and Nistico (2015) also derive a quadratic loss function in cashless economies with limited heterogeneity; unlike us, they all focus on an efficient equilibrium with insurance when calculating optimal policy. 
Proposition 2 Solving the welfare maximization problem is equivalent to solving:

$$
\min _{\left\{c_{t}^{P}, c_{t}^{N}, q_{t}, \pi_{t}\right\}} \frac{1}{2} E_{0} \sum_{t=0}^{\infty} \beta^{t}\{\underbrace{\tilde{\nu} \tilde{\pi}_{t}^{2}+(\gamma+\tilde{\varphi}) \hat{c}_{t}^{2}}_{R A N K}+\underbrace{\gamma n(1-n) \hat{q}_{t}^{2}}_{\text {inequality-T(H)ANK}}-\underbrace{\Lambda \hat{c}_{t}^{N}}_{\text {Novel }}\}
$$

where the optimal relative weights are:

$$
\tilde{\nu}=\nu\left(1-\frac{\nu}{2} \pi^{2}\right)^{-1} ; \tilde{\varphi}=\varphi\left(1-(1-n) \delta_{c}\right)^{-1} ; \Lambda=2(1-n) h\left(q^{\gamma}-1\right)
$$

The Proposition transparently illustrates the novel "liquidity-insurance" motive implied by our framework: a trade-off between insurance (inequality) and stabilization of inflation and aggregate demand. ${ }^{18}$ The last (linear) term pertains to lack of insurance: it shows the first-order welfare benefit of increasing $N$ 's welfare by increasing their consumption level: $\hat{\mathrm{c}}_{t}^{N} \equiv \hat{c}_{t}^{N}+\frac{1-\gamma}{2}\left(\hat{c}_{t}^{N}\right)^{2}$, where the second term is just a second-order correction. Intuitively, the weight $\Lambda$ is proportional to the steady-state distortion captured by $q^{\gamma}-1$ : the first-order benefit exists only insofar as the steady state is distorted to start with. This is analogous to the linear benefit of increasing output above the natural rate when the steady-state is first-order distorted in the standard New Keynesian model (see the next footnote). The distortion vanishes when the steady-state is egalitarian ( $p=h$, perhaps through a steady-state insurance scheme, if enough fiscal lump-sum instruments are available to undertake such policy) or, trivially, when $n=1$ (the standard cashless representative-agent NK model). Replacing the equilibrium $q$ reveals that $\Lambda$ is proportional to $\beta^{-1}-1+\pi$ : the distortion also becomes arbitrarily small when the steady state tends toward the Friedman rule, $\pi \rightarrow 1-\beta^{-1}$. Our result thus isolates the role of this monetary distortion, assuming a second-best world whereby fiscal policy does not achieve perfect insurance. Recall, however, that fiscal policy is already doing much redistribution along two dimensions: subsidizing firms to induce marginal cost pricing, and taxing participants only to finance that subsidy, thus redistributing de facto profit income. The only long-run difference left between the two types is proportional to the return on nominal assets, an inherently monetary distortion.

Because of the linear term in the loss function, second-order terms in the private constraints matter for welfare ${ }^{19}$ : as long as there is steady-state inequality, inflation and aggregate demand volatility matter for welfare beyond their direct effects. The reason is by now intuitively clear: when

\footnotetext{
${ }^{18}$ Note that $\tilde{\pi}_{t}=\pi_{t}+\pi$ is the inflation level, so the function is written so that target inflation is zero absent aggregate shocks, $\tilde{\pi}_{t}=0$. The optimal target is the optimal long-run inflation found in the Ramsey problem above, the equivalent of which is here the steady state of the solution of the relevant linear-quadratic problem.

${ }^{19}$ This is analogous to the linear benefit of increasing output above the natural rate when the steady-state is first-order distorted in the standard New Keynesian model. See Woodford (2003; Ch. 6), Benigno and Woodford (2005, 2012) and Schmitt-Grohe and Uribe (2007) for an analysis of this when the distortion pertains to monopolistic distortion, i.e. $\Phi>0$, including explanations of the second-order corrections that are necessary to correctly evaluate welfare.
} 
the steady state has $q>1$, increasing the consumption of non-participants provides a first-order welfare benefit; the only way to achieve this benefit, absent fiscal instruments, is monetary. As we show next, a quantitative analysis of optimal policy in a calibrated version of our model suggests that inflation volatility is desirable in this framework. Pursuing price stability instead, even around an optimally chosen inflation target, has large welfare costs.

As will become clear below, the optimal policy prescription is not to simply increase N's consumption; indeed, as we shall see other policies that imply higher consumption levels for $\mathrm{N}$ are suboptimal because they imply too much volatility. A second clarification is that inflation, because of the Pigou effect, is "bad" for $N$ as illustrated in (13): it erodes the value of their outstanding money balances. We shall see that inflation can nevertheless be optimal, despite this direct harmful effect, when it is a side-effect of liquidity used for insurance.

In Appendix B.6 we outline the main ingredients and implications of the model with endogenous income of participants as in Bilbiie (2008, 2019), which delivers an additional "New Keynesian cross" amplification channel. Therein, we show that the loss function in that model contains a linear term in both $c^{N}$ and $l^{N}$, namely $h c_{t}^{N}-l_{t}^{N}$. Thus, while there is a benefit in that model to increasing consumption of $\mathrm{N}$, there is also a cost insofar as this insurance-expansion is sustained by the same households working more hours. We will see that quantitatively this intuition implies that there will be less incentives to accommodate inflation, and less deviations from price stability in that model.

\section{Optimal Liquidity and Inflation: a Quantitative Evalua- tion}

We calibrate the model at quarterly frequency and follow, for common parameters pertaining to preferences and the supply side, the classic papers in optimal policy in NK models, Khan, King, and Wollman (2003) and Schmitt-Grohé and Uribe (2007): the inverse elasticity of labor supply is $\varphi=0.25$, and $\gamma=1$. The elasticity of substitution between goods is $\varepsilon=6$, and we first introduce the steady-state subsidy $\sigma=1 /(\varepsilon-1)$ to avoid steady-state distortions due to monopolistic competitionthus isolating our novel channel as a motivation for deviations from price stability. Both cited papers use different models of staggered pricing and assume that prices stay unchanged on average for 5 periods; this implies a Phillips curve slope (our $\psi$ ) of around 0.05. Given our $\varepsilon$, the price adjustment cost parameter that delivers the same $\psi$ is $\nu=100$. The discount factor is $\beta=0.98$, following other studies with heterogeneous agents (Eggertsson and Krugman, 2012; Curdia and Woodford, 2016); we consider larger values for robustness below. We use the same labor productivity process as Khan et al, with autocorrelation 0.95 and standard deviation $1 \%$.

Three parameters pertain to market incompleteness and money demand: the probabilities to keep participating $(\alpha)$ and non-participating $(\rho)$, and home production when non-participating (or 
unemployment benefits) $\delta$. Since we perfectly correlated financial market and labor market participation to obtain our tractable model, two calibrations are possible: one that targets financial market participation and money demand, and the other labor market variables. We use the former as a benchmark and report the latter for robustness.

We target three data features in our benchmark calibration. First, the number of participants $n$ : in the US economy roughly half of the population participates in financial markets, either directly or indirectly (Bricker et al, 2014), and this is stable over time. We thus take $n=0.5$, which implies the restriction $\alpha=\rho$. Second, the velocity of money (roughly speaking, $\mu^{-1}$ in our notation): considering a broad money aggregate, the quarterly velocity $(G D P / M 2)$ is around 2 over the period $1982-2007$ (chosen to avoid the zero lower bound period). Third, consumption inequality $q$ between participating and non-participating agents captures the lack of insurance due to market incompleteness. Since agents participate infrequently in financial markets and one cannot keep track of their participation status, it is hard to find an exact empirical counterpart to $q$. We take as a proxy the fall of nondurable consumption when becoming unemployed, which is estimated between $10 \%$ and $20 \%$ (e.g. ChodorowReich and Karabarbounis, 2014) and target the conservative value of $10 \%$ for $q^{-1}-1$ in our model. These three targets jointly imply $\alpha=\rho=0.9$, and $\delta=0.783$. Table 1 presents the parameters and implied Ramsey steady-state values for our target variables, which are determined by the Ramsey equilibrium conditions in the Appendix.

\subsection{Optimal Long-run Deviations from Price Stability}

The optimal asymptotic (steady-state) inflation rate is $\pi=-0.79 \%$. As expected, this is higher than the inflation implied by the Friedman Rule (which is $-2 \%$ ), because prices are sticky, just as in standard monetary models with sticky prices, e.g. Khan et al (2003). More equilibrium deflation occurs if prices are more flexible, labor is more elastic, and $\alpha$ is higher. The first two elements are standard (the former was first noticed by Chari Christiano Kehoe, 1997; see also Schmitt-Grohe and Uribe, 2004). The last part has a standard interpretation too: at given $n$, higher $\alpha$ implies more elastic money demand. As we will show below, less elastic money demand (lower $\alpha-n$ ) implies less optimal deflation - as in Khan, King and Wollman, although for a different theory of money demand.

\begin{tabular}{lllllllllll}
\multicolumn{1}{l}{ Preferences } & \multicolumn{1}{c}{ Production and price setting } & \multicolumn{3}{l}{ Heterogeneity } \\
\hline \hline$\beta$ & $\gamma$ & $\varphi$ & $\varepsilon$ & $\nu$ & $\rho^{a}$ & $\sigma_{a}$ & $\alpha$ & $\rho$ & $\delta$ \\
0.98 & 1 & 0.25 & 6 & 100 & 0.95 & 0.01 & 0.9 & 0.9 & 0.78 \\
Model outcome & & & & & & & & & \\
\hline \hline GDP/M2 & $n$ & $\left(c^{N}-c^{P}\right) / c^{P}$ & $\pi$ & $c^{p}$ & $c^{N}$ & $l$ & $m^{\text {tot }}$ & $q$ & \\
2 & $50 \%$ & $-11 \%$ & $-0.79 \%$ & 0.98 & 0.87 & 1.07 & 0.46 & 1.12 & \\
\hline \hline
\end{tabular}

Table 1: Baseline calibration 
What is the welfare cost of (steady-state) inflation? This is a classic question in monetary economics, going back at least to Bailey's (1956) calculation. ${ }^{20}$ We calculate this, in the Lucas (1987) tradition: in our economy, moving from a steady-state inflation rate [XR everything is quarterly] of $2 \%$ to the optimal rate of $-0.79 \%$ quarterly is equivalent to a permanent increase in consumption of $0.61 \%$-in line with (although slightly larger numbers than) e.g. Lucas (2000) and Imorohoroglu (1992), although slightly larger.

Our model's implications for optimal policy in the long run are thus rather standard. But in the short run, things are different and this is intimately related to the lack of insurance in our model: with long-run inequality $(q=1.12)$, the steady state is distorted and this has implications for short-run optimal policy.

\subsection{Liquidity-Insurance and Optimal (Short-Run) Price Stability}

The liquidity-insurance channel requires the central bank to accommodate some inflation volatility, as doing otherwise leads to large welfare losses. This is true in our economy even when the source of business cycles is a shock that, in the standard NK model with money demand but no inequality (insurance), generates no such trade-off: a plain-vanilla labor productivity shock.

Recall what happens in the baseline NK model in response to this shock: not much. A welfaremaximizing central bank keeps prices unchanged and inflation at zero, as this shock creates no trade-off: the central bank can close the output gap costlessly, a well-known result labeled "divine coincidence" by Blanchard and Galí (2007). This result changes but only slightly when the steady state is distorted ( $\Phi>0$ in our notation), as analyzed in detail by Benigno and Woodford (2005): productivity shocks then have a "cost-push" dimension, creating a trade-off. Quantitatively, however, this is moot-subject to one caveat mentioned in the next footnote. The same is true in models incorporating a variety of other frictions - in particular, in models with monetary frictions such as Khan, King, and Wollman (2003) and Schmitt-Grohe and Uribe (2004, 2007): price stability is a robust policy prescription. Even though these models do imply inflation volatility under the optimal Ramsey policy, the welfare cost of eliminating such volatility is generically negligible. ${ }^{21}$

This is no longer the case in our model: optimal Ramsey policy requires volatile inflation, and this volatility matters for welfare. To see the first part of this argument, consider the impulse responses to a productivity shock presented in Figure 1, for three economies. With a black solid line, we have

\footnotetext{
${ }^{20}$ Lucas (2000) found that reducing inflation from 10 to 0 percent annually results in a 1 percent increase in consumption. In a Bewley-type model, Imorohoglu (1992) showed that the welfare effects of inflation are larger in incomplete-markets economies.

${ }^{21}$ See for instance Table 2 in Schmitt-Grohé and Uribe (2007); see also Bilbiie, Fujiwara, and Ghironi (2014) for a result on optimal short-run price stability in a model with entry and variety, and a review of the literature using other distortions. As Benigno and Woodford (2005) show analytically price stability ceases to be optimal if, on top of $\Phi>0$, the share of government spending in steady-state output is also non-zero.
} 
our economy under optimal policy — obtained by solving (14). With a blue dashed line, we have our monetary economy under what we label "Strict inflation targeting" (SIT): the central bank perfectly stabilizes inflation around the Ramsey-optimal steady state inflation (this is implemented by a Taylor rule with large $\phi_{\pi}$ and the optimal $\pi^{*}$ target). Finally, we show with a red circle line optimal policy in a standard cashless equilibrium, ${ }^{22}$ a comparison with which illustrates the extent of risk-sharing provided by money in our model. All variables are in percentage deviation from steady state, except the inflation and interest rates, which are in deviation from steady state.

The responses of the cashless model are standard: inflation does not move, and output is equal to its natural rate. Since labor productivity affects only $\mathrm{P}$, their consumption increases (and so does inequality), and the nominal interest rate goes down.

In our monetary economy, the planner provides insurance: compared to the red circle line, the black solid line shows that the consumption of $\mathrm{N}$ increases (inequality decreases). The planner provides liquidity and interest rates fall; the result is inflation (due to the demand effect on firms), which erodes $N$ 's purchasing power (money balances) via the Pigou effect.

Consider now the allocation when this inflation is absent (blue dashed line): more liquidity is issued, and the real value of balances is much higher: thus, the consumption of $\mathrm{N}$ responds more, and is more volatile. Since the consumption of $\mathrm{P}$ is largely unchanged, the same is true for inequalityinsurance. We will now show that this extra volatility is costly in terms of aggregate welfare. ${ }^{23}$

Table 2 reports the standard deviations of the main variables for the (Ramsey-)optimal and SIT allocations. The volatility of inflation is comparable to Khan et al (2003). Because of limited risk-sharing, $N$ 's consumption volatility is higher than $P$ 's. More importantly, $N$ 's consumption volatility is higher under SIT than under optimal policy; as a result, the volatility of inequality is twice as large. This difference in volatilities translates into a moderate welfare cost of price stability (around the optimal asymptotic inflation rate): households need to be compensated by $0.08 \%$ of consumption every period in order to live in an economy with stable prices, rather than in one with optimal policy and inflation volatility, where we calculate these welfare costs following closely the

\footnotetext{
${ }^{22}$ Since in the non-monetary equilibrium the steady-state inflation rate is 0 , we recalibrated it to have the same steady state allocation. In particular, we reduce output by $\frac{\nu}{2} \pi^{2}$ and introduce a transfer between $N$ and $P$ households, such that the steady-state consumption and labor supply are the same in the monetary and non-monetary equilibrium, and only the steady-state inflation is different.

${ }^{23}$ It is by now well known, starting with the influential paper of King and Wolman (1999) and Woodford (2003), that welfare calculations depend crucially upon the initial values of the Lagrange multipliers - which can be set to 0 , or to their Ramsey steady-state values. Under the former choice, policy is not timeless-optimal: initial period $t_{0}$ inflation has no consequence for prior expectations, thus the policy chosen in any later period is not a continuation of $t_{0}$ policy. In the second case, policy is timeless-optimal in the sense of King and Wolman (1999) and Khan et al.(2003) (Woodford uses a different definition). The numers we report are for the former, $t_{0}$-optimal case; in the timeless-optimal case, the welfare losses are very close to zero in all cases; ses also Bilbiie, Fujiwara, and Ghironi (2014) for further discussion in a different context.
} 
method detailed in Schmitt-Grohe and Uribe (2007). ${ }^{24}$

Are these welfare costs "large"? It would be hard to argue so, even though the welfare cost of eliminating business cycles (that is, of providing the household with a certain, zero-volatility consumption path instead of the Ramsey-optimal but volatile path of consumption) are even smaller: that is, less than $0.001 \%$, even though consumption volatility is comparable to the data and to Lucas (1987), i.e. around $3 \%$ standard deviation. ${ }^{25}$

The bottomline seems to be that, while not negligible, the welfare costs of price stability in this baseline scenario are not that large - even though our long-run equilibrium is one with imperfect insurance (inequality), which for a planner is a distortion and implies a motive to provide liquidity. This distortion does not suffice to generate significant costs of price stability in our model, even though volatility has a first-order welfare effect through the level of $N$ 's consumption. In terms of our second-order approximation, this effect makes it "as if" the weight on inflation volatility in true Ramsey loss function were smaller than $\tilde{\nu}$, but the quantitative effect for our calibration is small.

\begin{tabular}{|c|c|c|c|c|c|}
\hline & \multicolumn{4}{|c|}{ Standard deviation (\%) } & \multirow{2}{*}{$\begin{array}{l}\text { Welfare (\%) } \\
\Delta^{W}\end{array}$} \\
\hline Economies & $\hat{c}^{P}$ & $\hat{c}^{N}$ & $\hat{q}$ & $\pi$ & \\
\hline \multicolumn{6}{|l|}{ Baseline } \\
\hline Ramsey & 2.6 & 2.9 & 0.7 & 0.05 & - \\
\hline SIT & 2.5 & 3.3 & 1.3 & 0 & 0.08 \\
\hline \multicolumn{6}{|c|}{ No SS inequality $(\beta \rightarrow 1)$} \\
\hline Ramsey & 2.5 & 3.1 & 0.6 & 0.05 & - \\
\hline SIT & 2.5 & 3.8 & 1.3 & 0 & 0.00 \\
\hline \multicolumn{6}{|c|}{ New Keynesian Cross } \\
\hline Ramsey & 2.8 & 3.3 & 1.1 & 0.02 & - \\
\hline SIT & 2.8 & 3.5 & 1.4 & 0 & 0.02 \\
\hline
\end{tabular}

Table 2: Standard deviations and welfare losses (percent)

That small inflation volatility translates into (albeit small) welfare gains in our model is due not so much to volatility itself as to imperfect insurance (inequality). To illustrate this, consider

\footnotetext{
${ }^{24}$ The welfare losses are similar for the two types of agents: our simplified model misses some of the distributional effects emphasized by the heterogeneous-agent literature that the welfare benefits of eliminating uncertainty are asymmetric among the poor, the rich, and the middle class (see Lucas 2003 for a review).

${ }^{25}$ Recall that the standard Lucas $(1987,2003)$ calculation delivering a cost of business cycles of $0.05 \%$ (still smaller than the cost of price stability here) is performed in a competitive, real model with exogenous labor. We argue that the right metric for assessing the benefit of eliminating business cycles is the same measure calculated for our Ramsey economy (any other assumption on policy will a fortiori be arbitrary). Recall also that the cost of business cycle measure is very sensitive to labor supply elasticity - indeed, business cycle volatility can even be beneficial in a standard RBC model with elastic labor. The welfare cost of fluctuations in a competitive version of our economy with inelastic labor and fixed money supply is $0.024 \%$.
} 
an economy where the steady-state distortion vanishes, $q \rightarrow 1$, which amounts to taking $\beta \rightarrow 1$ and re-calibrating $\delta$ to get the same steady-state money velocity; evidently, the optimal long-run inflation rate converges to 0 . As the bottom panel of Table 2 illustrates, the volatility of inflation under Ramsey policy in this economy is unchanged. Nevertheless, this volatility no longer means welfare: without a liquidity-insurance motive, the central bank can safely and costlessly pursue price stability (just as in Khan et al, 2003, and Schmitt-Grohe and Uribe, 2007).

The bottom panel of Table 2 adds the New Keynesian cross channel by making labor supply of $\mathrm{N}$ elastic and their income endogenous; constrained households thus have an additional margin to selfinsure in face of shocks. Notice that the subsidy to firms is paid by taxing all households uniformly (otherwise, there is no reason to self-insure through money in the steady-state equilibrium) In this economy, there is the additional amplification effect through the "New Keynesian cross" mentioned above (see Appendix B.6) and described in detail in Bilbiie (2008, 2019). Furthermore, steady-state inequality is higher because there is less fiscal redistribution (under our calibration, the consumption difference is 16\%) - so the distortion is larger, leading to a long-run Ramsey-optimal SS inflation rate of $-0.37 \%$. Monetary policy is more powerful, and there is also more insurance through the labor margin and hence less need to self-insure. In addition, as emphasized above, a linear term in the welfare function now penalizes expansions that are labor-driven, even when they provide insurance. In equilibrium, there is thus less inflation and inflation volatility because the liquidity-insurance motive is weaker. Consequently, the welfare costs of price stability are even smaller compared to the baseline.

\section{Robustness}

As a first robustness check we report the same outcomes for economies with different supply-side calibrations: more flexible prices $(\nu=50)$ and less elastic labor $(\varphi=1) .{ }^{26}$ The upper panel of Table 3 contains the results. Both the inflation volatility and its welfare benefit increase as prices become more flexible and labor supply more elastic. The reason is that with more flexible prices (lower $\nu$ ), the cost of using inflation is lower: in the limit, as prices become flexible, inflation essentially becomes a lump-sum tax — an insight originally due to Chari, Christiano, and Kehoe (1997) and also discussed by Schmitt-Grohe and Uribe (2004). But the numbers remain small.

\footnotetext{
${ }^{26}$ For each economy, in order to perform meaningful welfare comparisons we calibrate the discount factor $\beta$ and home production $\delta$, to start from the same steady state: this gives 0.973 and 0.79 for the first and 0.982 and 0.765 for the second calibration (results are similar when we keep these parameters unchanged).
} 


\begin{tabular}{lllllllll} 
& \multicolumn{7}{c}{ Standard deviation (\%) } & Welfare $(\%) \Delta^{W}$ \\
\hline Economies & $\pi^{S S}(\%)$ & & $\hat{c}^{P}$ & $\hat{c}^{N}$ & $\hat{q}$ & $\pi$ & & $H D \rightarrow S I T$ \\
\hline \hline Supply-side calibration & & & & & & & \\
$\nu=50$ & \multirow{2}{*}{-1.54} & Ramsey & 2.7 & 3.2 & 0.5 & 0.08 & - \\
& & SIT & 2.6 & 3.8 & 1.2 & 0 & 0.13 \\
$\varphi=1$ & \multirow{2}{*}{-0.6} & Ramsey & 2.1 & 2.7 & 0.6 & 0.04 & - \\
& & SIT & 2.0 & 3.0 & 0.9 & 0 & 0.03 \\
\hline \hline Labor market calibration & -0.36 & Ramsey & 3.0 & 5.1 & 2.1 & 0.02 & - \\
$(\alpha=0.95 ; \rho=0.5 ; \delta=0.5)$ & & SIT & 3.1 & 5.5 & 2.4 & 0 & 0.06 \\
\hline \hline
\end{tabular}

Table 3: Robustness analysis

The second alternative calibration we consider is based on labor market risk. Instead of matching financial market variables $(n, \mu$, and $q)$ as in our previous calibration, we draw on the labor market literature, in particular Shimer (2005) to find parameter values for $\alpha, \rho$, and $\delta$. At quarterly frequency, the job loss probability is $5 \%$ and the average job finding probability $50 \%$ for the post-war period-these two numbers imply $\alpha=0.95, \rho=0.5$ and thus $n=0.94$; the gross replacement ratio is set to $\delta / w=50 \%$ (see also Challe and Ragot, 2014). The bottom panel of Table 3 contains the results, assuming that all other parameters are as in the baseline; apart from the reported numbers, it is worth mentioning that the quarterly velocity of money is somewhat higher (2.33), and the fall in consumption when becoming unemployed is now $24 \%$ - in the upper range of the empirical estimates discussed above.

The optimal steady-state inflation rate is $-0.36 \%$ : there is less deflation than in the baseline calibration, for there is less money in circulation. This is similar to the optimal deflation rate obtained by Khan et al for their calibration with low money demand elasticity (obtained by estimating money demand over a shorter sample); indeed, since $\alpha$ is very close to $n$, our calibration also implies low money demand elasticity. The similarities go further: as in that model, optimal policy also implies lower inflation volatility under this calibration; and this smaller volatility is still associated with small welfare cost in our model (albeit larger than in Khan et al). Households are willing to sacrifice only $0.06 \%$ of consumption every period in order to live in an economy with optimally volatile inflation, rather than in an economy with stable prices; our result thus survives even in this economy with very low idiosyncratic risk calibrated to labor market data.

\subsection{A Complementarity: Liquidity-Insurance and the NK Monopoly Distortion}

All our previous calibrations assumed that there is an optimal subsidy that undoes the steadystate monopolistic distortion, $\Phi=0$, which allows isolating the novel channel that operates in our 
framework. The conclusion was that, quantitatively, that distortion is not by itself sufficient to generate significant deviations from price stability in response to productivity shocks.

Matters are different when the liquidity-insurance distortion coexists with the standard NK distortion, i.e. when monopolistic rents are left untouched by fiscal policy (there is no subsidy $\sigma=0$ ), which in our model also has distributional implications.

\begin{tabular}{llll} 
Economies & $\pi^{S S}(\%)$ & $s d(\pi)(\%)$ & $\Delta_{0}^{W}$ \\
\hline \hline Baseline & -1.54 & 0.06 & 0.48 \\
NK Cross & -0.4 & 0.02 & 0.16 \\
$\nu=50$ & -2.6 & 0.1 & 0.55 \\
$\varphi=1$ & -0.1 & 0.04 & 0.15 \\
$\beta \rightarrow 1$ & -0.7 & 0.05 & 0 \\
Labor Market & -0.6 & 0.02 & 0.33 \\
\hline \hline
\end{tabular}

Table 4: A distorted steady state, $\sigma=0$

As Table 4 shows, the welfare losses are now much larger, about five to seven times across calibrations. The two long-run distortions are thus complementary in generating significant losses from price stability: when our liquidity-insurance channel is at work $(q>1)$, the optimal deviations from price stability are very large indeed if supply-side distortions are also an issue $(\Phi>0)$. The notable exception is the case when there is long-run insurance (no steady-state inequality): the welfare loss is, again, zero - as our second-order approximation showed, the linear term in the loss function disappears in this case. Our framework thus identifies a novel channel that, when shut off, makes price stability again optimal even when the monopolistic distortion is large.

\section{Open-Market Operations}

In our model, it makes a difference whether monetary policy is conducted via helicopter drops or open market operations. How large is this difference? What are the implications for optimal monetary policy, and which means of issuing money is preferable from a welfare standpoint? To answer this, we now assume that instead of money being injected through a transfer, it is exchanged for bonds through open market operations OM. We maintain a consolidated budget constraint for the government:

$$
m_{t+1}^{t o t}+b_{t+1}+\tau_{t}=\frac{1}{1+\pi_{t}} m_{t}^{t o t}+\frac{1+i_{t-1}}{1+\pi_{t}} b_{t}
$$

where $\tau_{t}$ are taxes, and $b_{t+1}$ debt (when negative, these are assets). Using that money created by the central bank (money growth, or seigniorage) is given as before by (10) and replacing, we obtain:

$$
b_{t+1}+\tau_{t}+x_{t}=\frac{1+i_{t-1}}{1+\pi_{t}} b_{t}
$$


The way of money creation is dictated by how taxes/transfers adjust when money is introduced $x_{t}>0$. At one extreme we have the previous case of HD (within-period transfer $\tau_{t}=-x_{t}$ ). As another extreme, consider OM with one-period repayment: no transfer within the period $\tau_{t}=0$ but all debt gets repaid next period (to be precise, when money is issued and exchanged for bonds, this amounts not to repayment but to collecting, and transferring the proceeds):

$$
\tau_{t+1}=\frac{1+i_{t}}{1+\pi_{t+1}}\left(-x_{t}+\frac{1+i_{t-1}}{1+\pi_{t}} b_{t}\right) .
$$

The general case consists of a "tax rule" that ensures that the intertemporal budget equation holds as a constraint for any price level (Leeper, 1991; Woodford, 1996; see Leeper and Leith, 2016 for a review) - we outline this in the Appendix for completion. Insofar as optimal policy is concerned, however, the one-period-repayment case happens to also be the one that delivers the highest welfare with the class of OM policies; this is intuitive, because as we shall see OM imposes further constraints on the amount of insurance that monetary policy can achieve, and the faster the repayment, the better the insurance properties.

To understand the key difference between HD and OM, consider the budget constraint of $N$ under OM with one-period repayment:

$$
c_{t}^{N}=\delta+\frac{1+i_{t-1}}{1+\pi_{t}} x_{t-1}+\frac{1-\alpha}{n} \frac{m_{t}^{t o t}}{1+\pi_{t}}
$$

Monetary policy affects demand of $\mathrm{N}$ through two channels. First, the real balance, Pigou effect operates, regardless of the means of money creation: inflation erodes the real value of money balances, although the equilibrium inflation is different under HD and OM. Second, there is the key difference between HD and OM: period $t$ money creation $\left(x_{t}\right)$ in the HD case relaxes the budget constraint of $N$ within the period, whereas in the $O M$ case it affects the budget constraint of $N$-households only starting from the following period.

This implies that the Pigou effect does more work under OM, for it needs to compensate for the lack of a transfer: equilibrium inflation volatility is larger than under HD. When inflation volatility is costless (under flexible prices), this is largely irrelevant: both OM and HD allow reaching the same optimal allocation. But when prices are sticky and inflation is costly, a clear difference between OM and HD emerges, with important welfare consequences.

\subsection{Ramsey-Optimal Policy with Open Market}

For a welfare-maximizing central bank, implementing monetary policy through OM implies that there are additional instruments and constraints. In particular, the Ramsey problem now ought to include both new money $x_{t}$ and nominal interest $i_{t}$ as instruments; the additional constraints for the Ramsey planner are the budget constraint of $\mathrm{N}$ under OM (18), the Euler equation for bonds (5) and the definition of money growth (10). 
We compute Ramsey policy when monetary policy is conducted via OM with one-period repayment and assess the optimal way of money creation. ${ }^{27}$ Figure 2 illustrates the responses to a TFP shock under OM Ramsey policy, comparing them to the responses under HD Ramsey already illustrated in Figure 1.

A first main difference between HD and OM (illustrating the more general discussion above) is that when money is created by $\mathrm{OM} c^{N}$ does not move on impact, but increases sharpy only one period after the shock - in contrast to HD where it increases on impact. In other words, there is more risksharing for the aggregate risk when money is created under HD (albeit only on impact): we assess below the welfare cost generated by this difference. A second, related difference concerns inflation, which under OM first falls before increasing sharply (whereas it is much smoother under HD). With $\mathrm{OM}$, there is deflation today to provide insurance and increase $c^{N}$ - because the transfer cannot be used, in other words, the Pigou effect needs to bear the adjustment. But there is also expected inflation, which increases $c^{P}$ through the interest rate channel, i.e. intertemporal substitution. The planner ought to do this too, since otherwise P are hurt by deflation today, and the planner's ultimate objective is insurance. This generates volatile inflation under OM compared to HD. ${ }^{28}$

In a nutshell, aggregate demand is (optimally) more cyclical under HD, because money is transferred to non-participating households who have a high marginal propensity to consume. This translates into a more stable inflation under HD than under OM. Monetary policy through OM tries to make up for the lack of an instant transfer by exploiting the Pigou effect through inflation, which has perverse effects and can have large welfare costs. It is intuitive that, since monetary policy has a redistributive role in our model, HD is a preferable way to issue money because it has better insurance properties: it provides a direct transfer within the period, and it does not imply (inefficiently) relying upon the Pigou effect to do the job.

The question we ask is: how large is this? What is the welfare gain of switching, in response to the same shock, from OM to HD? In all economies we studied, this welfare cost is surprisingly smalleven when compared against the (even smaller, around $0.001 \%$ ) benefit of eliminating volatility reported above. As Table 5 shows, it ranges from $0.01 \%$ under the baseline model to above $0.05 \%$ in an economy with endogenous $\mathrm{N}$ labor and a distorted steady state. This is one order of magnitude smaller than the welfare cost of price stability, i.e. of not doing any insurance at all through inflation. ${ }^{29}$

\footnotetext{
${ }^{27}$ Numerical results support our previous intuition that this policy arrangement (with one-period repayment, i.e. $\left.\phi_{b}=1\right)$ delivers the highest welfare within the class of OM policies; this biases the results in favor of OM, that is it provides a lower bound on its welfare costs relative to HD.

${ }^{28}$ The immediate switch from deflation to inflation under OM occurs because we assume one-period bonds and the transfer of cental bank profits takes place within one period. Changing these assumptions would deliver a smoother path, but the intuition would be the same: first deflate, then inflate (because what matters for for $\mathrm{P}$ agents is the "long" rate).

${ }^{29}$ Using our previous computations, we can also assess the welfare costs of price stability instead of following the Ramsey-optimal policy, but conducted through OM. These follow directly by subtracting from the numbers in the last
} 


\begin{tabular}{|c|c|c|c|c|c|c|}
\hline & \multicolumn{5}{|c|}{ Std. dev. $(\%)$} & \multirow{2}{*}{$\begin{array}{l}\text { Welfare }(\%) \Delta^{W} \\
O M \rightarrow H D\end{array}$} \\
\hline Open-Market Ramsey & $\pi^{S S}(\%)$ & $\hat{c}^{P}$ & $\hat{c}^{N}$ & $\hat{q}$ & $\pi$ & \\
\hline \multicolumn{7}{|l|}{ Baseline } \\
\hline efficient SS & -0.79 & 2.6 & 2.7 & 1.1 & 0.05 & 0.01 \\
\hline distorted SS & -1.54 & 2.2 & 2.5 & 1.0 & 0.07 & 0.026 \\
\hline \multicolumn{7}{|l|}{ NK cross } \\
\hline efficient SS & -0.37 & 3.1 & 3.7 & 1.6 & 0.12 & 0.01 \\
\hline distorted SS & -0.41 & 2.7 & 3.1 & 1.5 & 0.09 & 0.052 \\
\hline
\end{tabular}

Table 5. Ramsey OM: Standard deviations and welfare losses

\section{Conclusions}

We study monetary policy in a sticky-price, New Keynesian model with heterogeneous households, incomplete markets and limited participation where money is essential as a self-insurance device. Liquidity and insurance (a limited notion of inequality) are intimately related in our model: today's liquidity (lower interest rates) implies tomorrow's insurance (and lower inequality). Aggregate demand in this model depends on: money, or liquidity, which relaxes the constraint of non-participating households and provides a saving vehicle for participating households; interest, because of intertemporal substitution by participating households; and prices, or inflation, because a Pigou effect operates for non-participating households, and (expected) inflation is the relevant return for holding liquidity for participants.

The link between liquidity and insurance is the keystone for optimal monetary policy in this model: a novel trade-off arises between providing liquidity for insurance purposes, and stabilization of inflation and real activity. We first illustrate this trade-off analytically by means of a secondorder approximation to the aggregate welfare function, in the New Keynesian tradition pioneered by Woodford (2003): there is a first-order benefit to providing insurance, insofar as the long-run equilibrium is characterized by a lack thereof (that is, by long-run consumption inequality). This first-order benefit of liquidity provision implies that the standard objective of eliminating inflation volatility take a back seat.

A quantitative assessment of this trade-off shows that in an economy with a long-run equilibrium characterized by imperfect insurance (consumption inequality), deviations from price stability are optimal. This holds, first, in the long run: the optimal inflation target should be between zero and the Friedman rule; this is no surprise - it is true in most monetary models. But in our framework, unlike in others, it is also true in the short run. Optimal policy implies inflation volatility in response

column of Table 5 the relevant number from Tables 2, 3 and 4 . We thus obtain, for the same four cases as in Table 5 : $0.07,0.45,0.01$, and 0.11 respectively. 
to (productivity) shocks that otherwise create no trade-off.

What is more, this volatility matters for welfare. A policy of stabilizing prices (albeit around the optimal inflation target) incurs a large welfare loss. This happens because short-run volatility has a first-order effect on constrained households: optimal policy requires giving less weight to inflation stabilization - which de facto implies giving more weight to constrained households. The welfare costs of short-run price stability are quantitatively significant only when our liquidity-insurance channel coexists with a by now classic to the NK framework: the "markup distortion", i.e. monopolistic rents that in our heterogeneous-household economy with limited participation also has distributional consequences. It is therefore the complementarity of these two distortions that calls for tolerating some inflation volatility as a side effect of liquidity provision.

This cannot be emphasized enough: the optimal policy prescription is not that the central bank should or needs to do anything radically different from what central banks are currently doing. Instead, it describes how, within that existing policy framework, this novel liquidity-insurance motive can be reinterpreted as a quantitative modification of the central banks' policy objectives - namely, more tolerance to inflation volatility when this is a side-effect of liquidity provision, and when monopolistic rents have distributional consequences. And once the optimal level of liquidity is provided, it matters surprisingly little for welfare purposes (through the lens of our calibrated quantitative model) whether it is injected through helicopter drops or open-market operations. That is even though the former is a less distortive, more direct way of providing insurance and the latter, by transferring resources to those who less need it, the unconstrained, does the opposite of insurance, which is the optimal policy prescription in this model.

\section{$7 \quad$ References}

Adao, B., I. Correia, and P. Teles, 2003. "Gaps and Triangles," Review of Economic Studies, 70(4), 699-713 Algan, Y. and X. Ragot. 2010., "Monetary Policy with Heterogeneous Agents and Borrowing Constraints." Review of Economic Dynamics, 13, 295-316

Algan, Y., E. Challe and X. Ragot, 2010. "Incomplete Markets and the Output-Inflation Trade-off", Economic Theory, 46(1), 2011, 55-84

Alvarez F., A. Atkeson and C. Edmond. 2009. "Sluggish Responses of Prices and Inflation to Monetary Shocks in an Inventory Model of Money Demand." The Quarterly Journal of Economics, MIT Press, vol. 124(3), pages 911-967

Alvarez, F., A. Atkeson and P. J. Kehoe. 2002. "Money, Interest Rates, and Exchange Rates with Endogenously Segmented Markets," Journal of Political Economy, University of Chicago Press, vol. 110(1), pages $73-112$,

Alvarez, F. and A. Atkeson, 1997. "Money and exchange rates in the Grossman-Weiss-Rotemberg model." Journal of Monetary Economics 40(3), pages 619-640 
Alvarez, F. and F. Lippi. 2009. "Financial Innovation and the Transactions Demand for Cash." Econometrica 77 (2): 363-402.

Alvarez, F. and F. Lippi. 2014. "The demand of liquid assets with uncertain lumpy expenditures." Journal of Monetary Economics, forthcoming.

Alvarez, F. and F. Lippi. 2014. "Persistent Liquidity Effects and Long-Run Money Demand." American Economic Journal: Macroeconomics 6(2), 71-107

Andrés, J., O. Arce and C. Thomas, 2013, "Banking competition, collateral constraints, and optimal monetary policy," Journal of Money, Credit and Banking, 45(s2)

Auclert, A. 2018, "Monetary Policy and the Redistribution Channel" American Economic Review

Auclert, A. and M. Rognlie, 2018, "Inequality and Aggregate Demand" Mimeo

Bacchetta, P., K. Benhima, and Y. Kalantzis, 2016 "Money and Capital in a persistent Liquidity Trap" American Economic Journal: Macroeconomics

Bailey, M., 1956, "The Welfare Cost of Inflationary Finance", Journal of Political Economy, 64(2), 93-110

Benigno, P., and M. Woodford. 2005. "Inflation Stabilization and Welfare: The Case of a Distorted Steady State." Journal of the European Economic Association, 3(6): 1185-1236.

Benigno, P., and M. Woodford. 2012. "Linear-Quadratic Approximation of Optimal Policy Problems." Journal of Economic Theory, 147(1): 1-42.

Bewley, T. F. 1977. "The Permanent Income Hypothesis: A Theoretical Formulation". Journal of Economic Theory 16: 252-92

Bewley, T. F. 1983 "A Difficulty with the Optimum Quantity of Money" Econometrica, 1983, 51(5), $1485-504$

Bhandari, A., D. Evans, M. Golosov, and T. Sargent, 2017, "Inequality, Business Cycles and MonetaryFiscal Policy", Mimeo

Bilbiie F. O. 2008. "Limited Asset Market Participation, Monetary Policy, and (Inverted) Aggregate Demand Logic." Journal of Economic Theory 140, 162-196.

Bilbiie F. O. 2018. "Monetary Policy and Heterogeneity: An Analytical Framework." CEPR DP

Bilbiie, F.O., 2019, "The New Keynesian Cross", Journal of Monetary Economics

Bilbiie, F. O., I. Fujiwara, and F. Ghironi, 2014, "Optimal Monetary Policy with Endogenous Entry and Product Variety." Journal of Monetary Economics, 64, 1-20

Bilbiie, F.O., and R. Straub, 2012, "Changes in the Output Euler Equation and Asset Markets Participation" Journal of Economic Dynamics and Control 36(11), 1659-1672

Bilbiie F. O. and R. Straub, 2013, "Asset Market Participation, Monetary Policy Rules and the Great Inflation", Review of Economics and Statistics, 95(2), pp 377-392

Bilbiie F. O., T. Monacelli and R. Perotti 2013, "Public Debt and Redistribution with Borrowing Constraints", The Economic Journal 2013, F64-F98, 02

Bilbiie F. O. and X. Ragot, 2019, "Helicopter Drops, Aggregate Demand, and Inequality" Mimeo

Braun, A. and T. Nakajima, 2012. "Uninsured Countercyclical Risk: An Aggregation Result And 
Application To Optimal Monetary Policy," Journal of the European Economic Association, 10(6), 14501474.

Bricker, J., L. Dettling, A. Henriques, J. Hsu, K. Moore, J. Sabelhaus, J. Thompson, and R. Windle. 2014. "Changes in U.S. Family Finances from 2010 to 2013: Evidence from the Survey of Consumer Finances," Federal Reserve Bulletin, 100(4)

Cao, S, C. A. Meh, J.V. Rıos-Rull and Y. Terajima. 2012. "Inflation, Demand for Liquidity and Welfare", Working Paper

Challe, E., 2019, "Uninsured unemployment risk and optimal monetary policy in a zero-liquidity economy," American Economic Journal: Macroeconomics

Challe, E. and X. Ragot, 2014 "Precautionary Saving Over the Business Cycle," The Economic Journal.

Challe, E., X. Ragot, J. Matheron, and J. Rubio-Ramirez, 2017, "Precautionary saving and aggregate demand", Quantitative Economics

Chari,V.V., L.J. Christiano, and P.J. Kehoe, 1991, Optimal fiscal and monetary policy: some recent results, Journal of Money, Credit, and Banking 23 519-539.

Chodorow-Reich, G. and L. Karabarbounis 2014, "The Cyclicality of the Opportunity Cost of Employment," Mimeo Harvard.

Clarida, R., J. Galí and M. Gertler, 1999, "The Science of Monetary Policy: A New Keynesian Perspective," Journal of Economic Literature, 37 1661-1707

Cloyne, J., C. Ferreira, and P. Surico 2015 "Monetary Policy when Households have Debt: New Evidence on the Transmission Mechanism" Review of Economic Studies

Coibion, O., Y. Gorodnichenko, L. Kueng and J. Silvia. 2012. "Innocent Bystanders? Monetary Policy and Inequality in the U.S", Forthcoming, Journal of Monetary Economics.

Correia, I. and P. Teles 1999, "The optimal inflation tax", Review of Economic Dynamics.

Cui, W. and S. Radde, 2016, "Search-Based Endogenous Asset Liquidity and the Macroeconomy", Mimeo UCL and ECB

Curdia, V. and M. Woodford, 2009, "Credit Frictions and Optimal Monetary Policy", Forthcoming, Journal of Monetary Economics.

Den Haan,W., Rendahl, P. and M. Riegler 2016, "Unemployment (Fears) and Deflationary Spirals", working paper.

Eggertsson G. and P. Krugman 2012, "Debt, Deleveraging, and the Liquidity Trap: A Fisher-MinskyKoo Approach, Quarterly Journal of Economics, 127(3): 1469-1513.

Friedman, M. 1969, The Optimum Quantity of Money, Macmillan

Fuerst, T. 1992. "Liquidity, loanable funds and economic activity." Journal of Monetary Economy 29(1),3-24.

Galí, J. 2008, "Monetary Policy, Inflation, and the Business Cycle: An Introduction to the New Keynesian Framework and Its Applications", Princeton University Press

Galí, J., D. López-Salido, and J. Vallés, 2007. "Understanding the Effects of Government Spending on Consumption". Journal of the European Economic Association, March, vol. 5 (1), 227-270. 
Gorea, D. and V. Midrigan, 2017, "Liquidity Constraints in the U.S. Housing Market." Mimeo NYU

Gornemann, N., K. Kuester, and M. Nakajima, 2012 "Monetary Policy with Heterogeneous Agents," Working Papers 12-21, Federal Reserve Bank of Philadelphia

Gottlieb, C. 2015, "On the Distributive Effects of Inflation" Mimeo

Green, E. 1994. "Individual-level randomness in a nonatomic population", working paper.

Grossman S.J and Weiss L. 1983. "A transactions-based model of the monetary transmission mechanism." American Economic Review. 73 (1983). 871-880.

Heathcote, J. and F. Perri, 2018, "Wealth and Volatility," Review of Economic Studies.

Imrohoroglu, A., 1992. The welfare cost of inflation under imperfect insurance. Journal of Economic Dynamics and Control 16, 79-91.

Ireland, P. 1996. "The role of countercyclical monetary policy." Journal of Political Economy 104(4), 704-723.

Kaplan, G. and G. Violante, 2014 "A Model of the Consumption Response to Fiscal Stimulus Payments," Econometrica

Kaplan, G., G. Violante, and J. Weidner, 2014 "The Wealthy Hand-to-Mouth," Brookings Papers on Economic Activity.

Kaplan, G., B. Moll and G. Violante 2018, "Monetary Policy According to HANK", American Economic Review

Kehoe, T., D. Levine, and M. Woodford, 1992, "The optimum quantity of money revisited," in Partha Dasgupta, Douglas Gale, Oliver Hart, and Eric Maskin, editors, The Economic Analysis of Markets and Games: Essays in Honor of Frank Hahn, MIT Press, 1992, 501-26.

Khan, A., R. G. King, and A. L. Wolman 2003. "Optimal Monetary Policy." Review of Economic Studies, 70(4), 825-860.

King, R. G., and A. L. Wolman, 1999 "What Should the Monetary Authority Do When Prices are Sticky?," in John B. Taylor, editor, Monetary Policy Rules, The University of Chicago Press, 1999, 349-398.

Leeper, E. M., 1991, "Equilibria under active and passive monetary and fiscal policies", Journal of Monetary Economics, 129-147

Le Grand, F. and Ragot, X. 2018 "Optimal fiscal policy with heterogeneous agents and aggregate shocks", mimeo, Sciencespo.

Lippi, F., S. Ragni and N. Trachter 2015. "Optimal monetary policy with heterogeneous money holdings." Journal of Economic Theory 339-368.

Lucas, R. E. Jr. 1987. "Models of Business Cycles." Oxford: Basil Blackwell.

Lucas R. E. Jr., 1990 "Liquidity and Interest Rates." Journal of Economic Theory 50, 237 - 264.

Lucas, R.E. Jr., 2000. "Inflation and Welfare". Econometrica 68, 247-274

Lucas, R. E., Jr. 2003 "Macroeconomic Priorities". American Economic Review 93 (1): 1-14.

Lucas, R. E., Jr., and N. L. Stokey, 1983, "Optimal Fiscal and Monetary Policy in an Economy without Capital," Journal of Monetary Economics 12, 55-93. 
McKay A. and R. Reis, "The Role of Automatic Stabilizers in the U.S. Business Cycle" , Econometrica, Vol. 84, No. 1, January 2016.

McKay A., Nakamura E. and J. Steinsson 2016, "The power of forward guidance revisited", American Economic Review.

Mehrling, P., 1995, "A Note on the Optimum Quantity of Money." Journal of Mathematical Economics 24(3): 249-58

Nistico, S., 2015, "Optimal monetary policy and financial stability in a non-Ricardian economy." Forthcoming, Journal of the European Economic Association

Nuno, G. and C. Thomas, 2017, "Optimal Monetary Policy with Heterogeneous Agents" Mimeo Bank of Spain

Patinkin, D. 1956, "Money, Interest and Prices: An Integration of Monetary and Value Theory", Second edition (1965), MIT Press

Pigou, A.C., 1943. "The Classical Stationary State". Economic Journal 53 (212): 343-351

Ragot, X. 2014. "The Case for a Financial Approach to Money Demand." Journal of Monetary Economics

Ragot, X. 2016. "Money and Capital Accumulation over the Business Cycle." Mimeo.

Ravn, M. and V. Sterk, 2013 "Job Uncertainty and Deep Recessions," forthcoming, Journal of Monetary Economics.

Rocheteau, G., and P. O. Weill 2011: "Liquidity in Frictional Asset Markets," Journal of Money, Credit and Banking, 43, 261-282.

Rocheteau, G., P. O. Weill and T. Wong, 2015, "A Tractable Model of Monetary Exchange with Ex-Post Heterogeneity" Mimeo UC Irvine, UCLA and Bank of Canada

Rocheteau, G., P. O. Weill and T. Wong, 2016, "Working through the Distribution: Money in the Short and Long Run" Mimeo UC Irvine, UCLA and Bank of Canada

Rotemberg, J. J. 1982, "Monopolistic Price Adjustment and Aggregate Output". Review of Economic Studies, 49(4), 517-531

Samuelson, P. 1958. "An Exact Consumption-Loan Model of Interest with or without the Social Contrivance of Money." Journal of Political Economy, 66, 467.

Scheinkman, J.A. and Weiss, L., 1986, "Borrowing constraints and aggregate economic activity", Econometrica, 54(1), 23-45.

Schmitt-Grohe, S. and M. Uribe, 2004, "Optimal Fiscal and Monetary Policy under Sticky Prices." Journal of Economic Theory, February 2004, 114(2): 198-230

Schmitt-Grohe, S. and M. Uribe, 2007, "Optimal Simple and Implementable Monetary and Fiscal Rules." Journal of Monetary Economics 54, 6

Sheedy, K. D. 2014, "Debt and Incomplete Financial Markets: A Case for Nominal GDP Targeting," Brookings Papers on Economic Activity, 301-373

Shimer, R. 2005. "The cyclical behaviour of equilibrium employment and vacancies." American Economic Review 95(1), pp. 25-49 
Sterk, V. and S. Tenreyro, 2016, "The Transmission of Monetary Policy through Redistributions and Durable Purchases" Mimeo UCL and LSE

Vissing-Jorgensen, A. 2002. "Limited Asset Market Participation and the Elasticity of Intertemporal Substitution" Journal of Political Economy

Wallace, N. 1981. A Modigliani-Miller Theorem for Open-Market Operations, The American Economic Review, Vol. 71, No. 3 (Jun., 1981), pp. 267-274

Wallace, N. 2014. "Optimal money-creation in pure-currency economies: a conjecture." Quarterly Journal of Economics 129(1), 259-274.

Weill, P. O. 2007 "Leaning Against the Wind," Review of Economic Studies, 74(4), 1329-1354.

Werning, I., 2015, "Incomplete Markets and Aggregate Demand", Mimeo MIT

Woodford, M. 1990. "Public Debt as Private Liquidity" American Economic Review 80(2), pp. 382-88

Woodford, M. 1996. "Controlling the Public Debt: A Requirement for Price Stability?" NBER Working Paper

Woodford, M. 1998. "Doing Without Money: Controlling Inflation in a Post-Monetary World," Review of Economic Dynamics, 1: 173-219

Woodford, M., 2003, Interest and Prices: Foundations of a Theory of Monetary Policy, Princeton University Press

Woodford, M. 2012. "Methods of Policy Accommodation at the Interest-Rate Lower Bound", Jackson Hole Symposium. 


\section{A Model Summary}

The equations describing our model in the general case are:

$$
\begin{aligned}
u^{\prime}\left(c_{t}^{P}\right) & =\beta E \frac{1+i_{t}}{1+\pi_{t+1}} u^{\prime}\left(c_{t+1}^{P}\right) \\
u^{\prime}\left(c_{t}^{P}\right) & =\beta E\left[\alpha u^{\prime}\left(c_{t+1}^{P}\right)+(1-\alpha) u^{\prime}\left(c_{t+1}^{N}\right)\right] \frac{1}{1+\pi_{t+1}} \\
u^{\prime}\left(c_{t}^{N}\right) & \geq \beta E\left[(1-\rho) u^{\prime}\left(c_{t+1}^{P}\right)+\rho u^{\prime}\left(c_{t+1}^{N}\right)\right] \frac{1}{1+\pi_{t+1}} \\
c_{t}^{P}+\tilde{m}_{t+1}^{P} & =w_{t} l_{t}^{P}-\tau_{t}^{P}+\frac{1}{n} d_{t}+\frac{\alpha}{1+\pi_{t}} \tilde{m}_{t}^{P}+\frac{1-\alpha}{1+\pi_{t}} \tilde{m}_{t}^{N} \\
\tilde{m}_{t+1}^{N}+c_{t}^{N} & =\delta-\tau_{t}^{N}+\frac{1-\rho}{1+\pi_{t}} \tilde{m}_{t}^{P}+\frac{\rho}{1+\pi_{t}} \tilde{m}_{t}^{N} \\
\pi_{t}\left(1+\pi_{t}\right) & =\beta E_{t}\left[\left(\frac{c_{t}^{P}}{c_{t+1}^{P}}\right)^{\gamma} \frac{Y_{t+1}}{Y_{t}} \pi_{t+1}\left(1+\pi_{t+1}\right)\right]+\frac{\varepsilon-1}{\nu}\left[\frac{\varepsilon}{\varepsilon-1} \frac{w_{t}}{A_{t}}-(1+\sigma)\right] \\
Y_{t} & =n A_{t} l_{t}^{P} \\
w_{t} & =\chi\left(l_{t}^{P}\right)^{\varphi}\left(c_{t}^{P}\right)^{\gamma} \\
d_{t} & =\left(1+\sigma-\frac{w_{t}}{A_{t}}-\frac{\nu}{2} \pi_{t}^{2}\right) Y_{t} \\
\tilde{m}_{t+1}^{N} & =\frac{n \tilde{m}_{t}^{P}+(1-n) \tilde{m}_{t}^{N}}{1+\pi_{t}}+x_{t} \\
\tau_{t} & =-x_{t} \\
\tau_{t}^{P} & =\frac{\omega}{n} \tau_{t} ; \tau_{t}^{N}=\frac{1-\omega}{1-n} \tau_{t}^{N} \\
\tilde{m}_{t+1}^{P}+(1-n & 0 \\
\tilde{m}_{t+1} & \\
& \\
\tilde{m}_{t+1} & \\
&
\end{aligned}
$$

where $m_{t+1}^{C B}$ is a period $t$ monetary shock (new money created) and $A_{t}$ exogenous labor productivity. The economy resource constraint follows by Walras' law:

$$
n c_{t}^{P}+(1-n) c_{t}^{N}=\left(1-\frac{\nu}{2} \pi_{t}^{2}\right) Y_{t}+(1-n) \delta
$$

and can replace (for instance) the $\mathrm{P}$ agents' budget constraint in the system above.

An equilibrium of the economy is a sequence $\left\{c_{t}^{P}, c_{t}^{N}, c_{t} \pi_{t}, x_{t}, \tilde{m}_{t+1}^{P}, \tilde{m}_{t+1}^{N}, w_{t}, l_{t}^{P}, \tau_{t}^{P}, \tau_{t}^{N}, \tau_{t}, d_{t}, Y_{t}\right\}$ satisfying the previous conditions. Assuming that nominal bonds are in zero net supply, we guessand-verify the structure of the equilibrium with $\tilde{m}_{t}^{N}=0$, i.e. non-participating households never hold money at the end of the period. The conditions for households in the $N$ island not to hold money, which we check holds in the equilibrium we consider, is:

$$
u^{\prime}\left(c_{t}^{N}\right)>\beta E\left[(1-\rho) u^{\prime}\left(c_{t+1}^{P}\right)+\rho u^{\prime}\left(c_{t+1}^{N}\right)\right] \frac{1}{1+\pi_{t+1}} .
$$


Consider the conditions for a monetary equilibrium to exist. ${ }^{30}$ In a monetary steady-state, $N$ agents do not hold money when $1+\pi>\beta$, while $P$ agents save in money comparing the gain to self-insure and the opportunity cost (deflation). Thus, we have $c^{P}>c^{N}$ and $q>1$. Since it is costly for $P$ agents to save (the return on money is lower than the discount factor), they rationally choose not to perfectly self-insure. Using this inequality in the condition (7), we have $u^{\prime}\left(c^{N}\right)>\left[(1-\rho) u^{\prime}\left(c^{P}\right)+\rho u^{\prime}\left(c^{N}\right)\right] \frac{\beta}{1+\pi}: N$ agents do not hold money at the end of each period, and $\tilde{m}^{N}=0$. In steady state, positive money demand requires the restriction that the outside option not be too good:

$$
\delta_{c}<\bar{\delta}=h=\left[1+n\left(\left(\frac{1+\pi-\alpha \beta}{\beta(1-\alpha)}\right)^{\frac{1}{\gamma}}-1\right)\right]^{-1}
$$

Under a Taylor rule, the steady-state inflation rate $\pi$ is determined by the central bank's target and the above condition is parametric. Under Ramsey policy, $\pi$ is endogenous (it depends, among other things, on $\delta$ ) and the above condition defines a threshold implicitly.

\section{B Derivations and Proofs}

\section{B.1 New Keynesian Phillips curve}

The intermediate goods producers solve:

$$
\max _{P_{t}(z)} E_{0} \sum_{t=0}^{\infty} Q_{0, t}^{s}\left[(1+\sigma) P_{t}(z) Y_{t}(z)-W_{t} l_{t}(z)-\frac{\nu}{2}\left(\frac{P_{t}(z)}{P_{t-1}(z)}-1\right)^{2} P_{t} Y_{t}\right]
$$

where $Q_{0, t}^{s} \equiv \beta_{s}^{t}\left(P_{0} c_{0}^{P} / P_{t} c_{t}^{P}\right)^{\gamma}$ is the marginal rate of intertemporal substitution of participants between times 0 and $t$, and $\sigma$ is a sales subsidy. Firms face demand for their products from two sources: consumers and firms themselves (in order to pay for the adjustment cost); the demand function for the output of firms $z$ is $Y_{t}(z)=\left(P_{t}(z) / P_{t}\right)^{-\varepsilon} Y_{t}$. Substituting this into the profit function,

\footnotetext{
${ }^{30}$ Monetary variables are generally not uniquely determined. There always exists an equilibrium of our model where money has no value. If agents anticipate that money is not traded in the future, they do not accept money today and the price of money is 0 . The reason for the existence of a non-monetary equilibrium is the same as in the monetary overlapping-generations model of Samuelson (1958). In such a cashless equilibrium, the consumption of $N$ agents is $c^{N}=\delta_{t}$ in each period. The consumption of $P$ agents is easily determined; this is akin to the standard cashless New Keynesian model studied in Woodford (2003).
} 
the first-order condition is, after simplifying:

$$
\begin{aligned}
0 & =Q_{0, t}\left(\frac{P_{t}(z)}{P_{t}}\right)^{-\varepsilon} Y_{t}\left[(1+\sigma)(1-\varepsilon)+\varepsilon \frac{W_{t}}{P_{t}}\left(\frac{P_{t}(z)}{P_{t}}\right)^{-1}\right] \\
& -Q_{0, t} \nu P_{t} Y_{t}\left(\frac{P_{t}(z)}{P_{t-1}(z)}-1\right) \frac{1}{P_{t-1}(z)}+ \\
& +E_{t}\left\{Q_{0, t+1}\left[\nu P_{t+1} Y_{t+1}\left(\frac{P_{t+1}(z)}{P_{t}(z)}-1\right) \frac{P_{t+1}(z)}{P_{t}(z)^{2}}\right]\right\}
\end{aligned}
$$

In a symmetric equilibrium all producers make identical choices (including $P_{t}(z)=P_{t}$ ); defining net inflation $\pi_{t} \equiv\left(P_{t} / P_{t-1}\right)-1$, and noticing that $Q_{0, t+1}=Q_{0, t} \beta\left(c_{t}^{P} / c_{t+1}^{P}\right)^{\gamma}\left(1+\pi_{t+1}\right)^{-1}$, equation (20) becomes:

$$
\begin{aligned}
\pi_{t}\left(1+\pi_{t}\right) & =\beta E_{t}\left[\left(\frac{c_{t}^{P}}{c_{t+1}^{P}}\right)^{\gamma} \frac{Y_{t+1}}{Y_{t}} \pi_{t+1}\left(1+\pi_{t+1}\right)\right]+ \\
& +\frac{\varepsilon-1}{\nu}\left[\frac{\varepsilon}{\varepsilon-1} \frac{w_{t}}{A_{t}}-(1+\sigma)\right]
\end{aligned}
$$

\section{B.2 Friedman Rule with flexible prices}

First we show that, as in other monetary economies, the price level is indeterminate at the Friedman rule. For $i=0$, the steady state implies $1+\pi=\beta ; c^{P}=c^{N}=c$ and $m^{C B}=\left(1-\beta^{-1}\right)\left(n \tilde{m}^{P}+(1-n) \tilde{m}^{N}\right)$. The real allocation is determined by $1=\chi\left(l^{P}\right)^{\varphi}\left(c^{P}\right)^{\gamma}, c=n l^{p}+(1-n) \delta$ and

$c=\delta+\frac{1}{\beta}\left(1-\rho-(1-(1-\beta) \phi)\left(\frac{1}{\beta}-1\right) n\right) \tilde{m}^{P}+\frac{1}{\beta}\left(\rho-\beta-(1-(1-\beta) \phi)\left(\frac{1}{\beta}-1\right)(1-n)\right) \tilde{m}^{N}$

There is indeterminacy, even though the real variables $c$ and $l^{p}$ are uniquely determined as the steady-state first-best values: the monetary variables $\tilde{m}^{P}$ and $\tilde{m}^{N}$ must satisfy only one equation, so the real quantity of money is indeterminate.

Second, we show (in the nonlinear model) convergence to the first-best allocation (when $\nu=0$ ) if $2-\alpha-\rho>\beta^{-1}-1$; the steady-state allocation converges to the first best when $i \longrightarrow 0^{+}$. In this case, $1+\pi \longrightarrow \beta^{+}$. For $0<k<1$, define $\hat{l}_{t}(k)$ as the unique solution to the equation:

$$
(n+(1-n) k)\left(\frac{A_{t}}{\chi}\right)^{\frac{1}{\gamma}}\left(\hat{l}_{t}^{P}(k)\right)^{-\frac{\varphi}{\gamma}}=A_{t} \hat{l}_{t}^{p}(k)+(1-n) \delta_{t}
$$

As the left hand side is decreasing and the right hand side increasing in $\hat{l}_{t}^{p}$, there always exists a positive solution to the previous equation, whatever $A_{t}, \delta_{t}>0$. Define $\hat{c}_{t}^{P}(k)$ as:

$$
\hat{c}_{t}^{P}(k) \equiv \frac{n A_{t} l_{t}^{p}+(1-n) \delta_{t}}{n+(1-n) k}
$$

For any $k<1$, we show that this can reach allocations where $c_{t}^{P}=\hat{c}_{t}^{P}(k), c_{t}^{N}=k c_{t}^{p}(k)$ and $l_{t}=\hat{l}_{t}^{P}(k)$. When $k$ equals 1 , the allocation is exactly the first-best allocation. When $k$ approaches 
1, the allocation can be made arbitrarily close to the first-best allocation and the nominal interest rate $i_{t}$ tends toward $0^{+}$. Take now the model equations from Appendix A, for the case of flexible prices $\nu=0$ and using the money market equilibrium to substitute for $\tilde{m}_{t+1}^{P}$. We proceed by guess and verify. At any period, the variables $m_{t}^{C B}$ and $\tilde{m}_{t}^{P}$ are predetermined. As a consequence, assume that the period $t$ money creation $m_{t+1}^{C B}$ is determined by the following law:

$$
m_{t+1}^{C B}=k \hat{c}_{t}^{P}-\delta-\frac{1}{\beta} \frac{u^{\prime}\left(\hat{c}_{t-1}^{P}\right)}{u^{\prime}\left(\hat{c}_{t}^{P}\right)} \frac{1-\rho}{\alpha+(1-\alpha) k^{-\gamma}} \tilde{m}_{t}^{P}
$$

It is easy to show that the allocation $c_{t}^{P}=\hat{c}_{t}^{P} ; c_{t}^{N}=k \hat{c}_{t}^{P} ; i_{t}=\alpha+(1-\alpha) k^{-\gamma} ; \tau_{t}=-m_{t+1}^{C B}$ and

$$
1+\pi_{t}=\beta\left[\alpha+(1-\alpha) k^{-\gamma}\right] \frac{u^{\prime}\left(\hat{c}_{t}^{P}\right)}{u^{\prime}\left(\hat{c}_{t-1}^{P}\right)}
$$

is an equilibrium of the model, because it satisfies all equations. The equilibrium is locally unique, which can be shown in a standard way by perturbation methods in a more general case.

\section{B.3 Optimal Ramsey Policy}

The constraints of the Ramsey planner are (these are the model equations, with relevant substitutions and using the economy resource constraint instead of the $\mathrm{P}$ budget constraint):

$$
\begin{aligned}
u^{\prime}\left(c_{t}^{P}\right) & =\beta E_{t}\left[\frac{\alpha u^{\prime}\left(c_{t+1}^{P}\right)+(1-\alpha) u^{\prime}\left(c_{t+1}^{N}\right)}{1+\pi_{t+1}}\right] \\
n c_{t}^{P}+(1-n) c_{t}^{N} & =\left(1-\frac{\nu}{2} \pi_{t}^{2}\right) n A_{t} l_{t}^{P}+(1-n) \delta \\
\pi_{t}\left(1+\pi_{t}\right) & =\beta E_{t}\left[\left(\frac{c_{t}^{P}}{c_{t+1}^{P}}\right)^{\gamma} \frac{A_{t+1} l_{t+1}^{P}}{A_{t} l_{t}^{P}} \pi_{t+1}\left(1+\pi_{t+1}\right)\right]+\frac{\varepsilon-1}{\nu}\left[\frac{\varepsilon}{\varepsilon-1} \frac{\chi\left(l_{t}^{P}\right)^{\varphi}\left(c_{t}^{P}\right)^{\gamma}}{A_{t}}-(1+\sigma)\right] \\
c_{t}^{N} & =\delta_{t}+\left(m_{t+1}^{t o t}-\frac{m_{t}^{t o t}}{1+\pi_{t}}\right)+\frac{1}{1+\pi_{t}} \frac{1-\alpha}{1-n} m_{t}^{t o t} \\
u^{\prime}\left(c_{t}^{P}\right) & =\beta E_{t} \frac{1+i_{t}}{1+\pi_{t+1}} u^{\prime}\left(c_{t+1}^{P}\right)
\end{aligned}
$$

When money is created through helicopter-drop, within-period transfers, only the first three equations above are constraints for the Ramsey planner. ${ }^{31}$ Indeed, once $c^{P}$ and $\pi$ are known, $i$ follows from the Euler equation for bonds (which hence will not bind as a constraint). Similarly, once the allocation of the consumption of $\mathrm{N}$ and inflation have been chosen, the quantity of money delivering it can be recovered through the following equation:

$$
c_{t}^{N}=\delta_{t}+m_{t+1}^{t o t}-\frac{\alpha-n}{1-n} \frac{m_{t}^{t o t}}{1+\pi_{t}},
$$

\footnotetext{
${ }^{31}$ Whereas with open-market operations, all of the above equations are constraints; we analyze this case and provide a welfare comparison in the companion paper.
} 
where, implicitly, we concentrate only on equilibria where money is used.

The central bank chooses $c^{P}, c^{N}, l^{P}, \pi$ to maximize the objective defined in the text, subject to the above system of 3 constraints which we denoted in text by $\Gamma_{t}$ and write here explicitly for reference:

$$
\begin{aligned}
& \max _{\left\{c_{t}^{P}, c_{t}^{N}, l_{t}^{P}, \pi_{t}\right\}} E_{0} \sum_{t=0}^{\infty} \beta^{t}\left\{n\left[u\left(c_{t}^{P}\right)-\chi \frac{\left(l_{t}^{P}\right)^{1+\varphi}}{1+\varphi}\right]+(1-n)\left[u\left(c_{t}^{N}\right)-\chi \frac{\delta^{1+\varphi}}{1+\varphi}\right]\right. \\
& +\omega_{1 t}\left[\left(1+\pi_{t+1}\right)\left(c_{t}^{P}\right)^{-\gamma}-\beta \alpha\left(c_{t+1}^{P}\right)^{-\gamma}-\beta(1-\alpha)\left(c_{t+1}^{N}\right)^{-\gamma}\right] \\
& +\omega_{2 t}\left[n c_{t}^{P}+(1-n) c_{t}^{N}-\left(1-\frac{\nu}{2} \pi_{t}^{2}\right) n A_{t} l_{t}^{P}-(1-n) \delta\right] \\
& \left.+\omega_{3 t}\left[\pi_{t}\left(1+\pi_{t}\right)-\beta E_{t}\left[\left(\frac{c_{t}^{P}}{c_{t+1}^{P}}\right)^{\gamma} \frac{Y_{t+1}}{Y_{t}} \pi_{t+1}\left(1+\pi_{t+1}\right)\right]-\frac{\varepsilon}{\nu}\left(\frac{\chi\left(l_{t}^{P}\right)^{\varphi}\left(c_{t}^{P}\right)^{\gamma}}{A_{t}}+\Phi-1\right)\right]\right\}
\end{aligned}
$$

The solution is a system of 4 first-order conditions and 3 constraints, for 4 variables and 3 co-states (the Lagrange multipliers on the constraints). The first-order conditions of the Ramsey problem are for each variable respectively:

$$
\begin{aligned}
0 & =n\left(c_{t}^{P}\right)^{-\gamma}-\gamma \omega_{1 t}\left(1+\pi_{t+1}\right)\left(c_{t}^{P}\right)^{-\gamma-1}+\gamma \omega_{1 t-1} \alpha\left(c_{t}^{P}\right)^{-\gamma-1} \\
& +\omega_{2 t} n-\frac{\varepsilon}{\nu} \gamma \omega_{3 t} \frac{\chi\left(l_{t}^{P}\right)^{\varphi}\left(c_{t}^{P}\right)^{\gamma-1}}{A_{t}} \\
0 & =(1-n)\left(c_{t}^{N}\right)^{-\gamma}+\gamma \omega_{1 t-1}(1-\alpha)\left(c_{t}^{N}\right)^{-\gamma-1}+\omega_{2 t}(1-n) \\
0 & =-n \chi\left(l_{t}^{P}\right)^{\varphi}-\omega_{2 t}\left(1-\frac{\nu}{2} \pi_{t}^{2}\right) n A_{t}-\omega_{3 t} \varphi \frac{\varepsilon}{\nu} \frac{\chi\left(l_{t}^{P}\right)^{\varphi-1}\left(c_{t}^{P}\right)^{\gamma}}{A_{t}} \\
0 & =\omega_{1 t-1} \beta^{-1}\left(c_{t-1}^{P}\right)^{-\gamma}+\omega_{2 t} \nu \pi_{t} n A_{t} l_{t}^{P}+\left(\omega_{3 t}-\omega_{3 t-1}\right)\left(1+2 \pi_{t}\right)
\end{aligned}
$$

plus the three constraints with complementary slackness.

A steady-state of the Ramsey problem is defined by:

$$
\begin{gathered}
\omega_{1}=0 \text { or }\left(c^{P}\right)^{-\gamma}=\frac{1-\alpha}{\frac{1+\pi}{\beta}-\alpha}\left(c^{N}\right)^{-\gamma} \\
\omega_{2}=0 \text { or } n c_{t}^{P}+(1-n) c_{t}^{N}=\left(1-\frac{\nu}{2} \pi^{2}\right) n l^{P}+(1-n) \delta \\
\omega_{3}=0 \text { or } \pi(1+\pi)=\frac{\varepsilon}{\nu(1-\beta)}\left[\chi\left(l^{P}\right)^{\varphi}\left(c^{P}\right)^{\gamma}-(1-\Phi)\right] \\
0=n\left(c^{P}\right)^{-\gamma}-\gamma \omega_{1}(1+\pi-\alpha)\left(c^{P}\right)^{-\gamma-1}+\omega_{2} n-\frac{\varepsilon}{\nu} \gamma \omega_{3} \chi\left(l^{P}\right)^{\varphi}\left(c^{P}\right)^{\gamma-1} \\
0=(1-n)\left(c^{N}\right)^{-\gamma}+\gamma \omega_{1}(1-\alpha)\left(c^{N}\right)^{-\gamma-1}+\omega_{2}(1-n) \\
0=-n \chi\left(l^{P}\right)^{\varphi}-\omega_{2}\left(1-\frac{\nu}{2} \pi^{2}\right) n-\omega_{3} \frac{\varepsilon}{\nu}_{\nu} \chi\left(l^{P}\right)^{\varphi-1}\left(c^{P}\right)^{\gamma} \\
0=\omega_{1} \beta^{-1}\left(c^{P}\right)^{-\gamma}+\omega_{2} \nu \pi n l^{P}
\end{gathered}
$$


The Proof of the proposition pertaining to optimal long-run inflation is now immediate. With flexible prices $\nu=0$ and optimal subsidy, the only solution to the above system of equations is perfect insurance through the Friedman Rule:

$$
\frac{1+\pi}{\beta}=1 \rightarrow c^{P}=c^{N}=c
$$

With sticky prices and inelastic labor $\varphi \rightarrow \infty$, the intratemporal optimality condition disappears from the set of constraints, labor is fixed, and it can be easily shown that inflation tends to zero $(\pi=0$ solves the above system).

Computing the welfare cost To calculate the welfare cost of inflation, we proceed in the standard way pioneered by Lucas (1987). Denote with an upper-script $S S$ the allocation for the inflation rate $\pi^{S S}$ and no shock. We denote the welfare of an economy where inflation is, say $\pi^{*}$, as $V^{*}$. We then compute the proportional decrease in consumption for all households in the economy with inflation rate $\pi^{*}$ to equalize the two welfare measures. Formally we compute $\Delta^{W}$ to have:

$E_{0} V^{*}=E_{0} \sum_{t=0}^{\infty} \beta^{t}\left\{n\left[u\left(\left(1-\Delta^{W}\right) c_{t}^{P S S}\right)-\chi \frac{\left(l_{t}^{P S S}\right)^{1+\varphi}}{1+\varphi}\right]+(1-n)\left[u\left(\left(1-\Delta^{W}\right) c_{t}^{N S S}\right)-\chi \frac{\delta^{1+\varphi}}{1+\varphi}\right]\right\}$

\section{B.4 Open Market Operations and Ramsey Problem}

The general form of money issuance under OM is captured by a "fiscal rule" that insures that the intertemporal government equation holds as a constraint for any price level, for example

$$
\tau_{t}=\phi_{b} \frac{1+i_{t-1}}{1+\pi_{t}} b_{t}-\phi_{x} x_{t}
$$

This nests the two extreme cases considered in text HD with $\phi_{x}=1$ and OM with one-period repayment. More generally, the coefficient $\phi_{b}$ captures how fast money is issued in the economy once the $\mathrm{OM}$ operation took place. We checked numerically that the value of $\phi_{b}$ delivering the highest welfare is 1, i.e. one-period repayment, the intuition being the one provided in text. Rigorously, the Ramsey problem becomes with $\mathrm{OM}$ one of choosing the allocation $\left\{c_{t}^{P}, c_{t}^{N}, l_{t}^{P}, \pi_{t}, m_{t+1}^{\text {tot }}, i_{t}\right\}$ to maximize a Lagrangian similar to the one in (14) but :

$$
E_{0} \sum_{t=0}^{\infty} \beta^{t}\left\{n\left[u\left(c_{t}^{P}\right)-\chi \frac{\left(l_{t}^{P}\right)^{1+\varphi}}{1+\varphi}\right]+(1-n)\left[u\left(c_{t}^{N}\right)-\chi \frac{\delta^{1+\varphi}}{1+\varphi}\right]+\omega_{t} \Gamma_{t}\right\}
$$


where $\omega_{t}$ is the vector of costate, Lagrange multipliers, one for each constraint in $\Gamma_{t}$-which include, other than the constraints with HD, the additional:

$$
\begin{aligned}
c_{t}^{N} & =\delta-\tau_{t}+\frac{1-\alpha}{1-n} \frac{m_{t}^{t o t}}{1+\pi_{t}} \\
b_{t+1}+\tau_{t}+x_{t} & =\frac{1+i_{t-1}}{1+\pi_{t}} b_{t} \\
x_{t} & =m_{t+1}-\frac{1}{1+\pi_{t}} m_{t} \\
\tau_{t} & =\phi_{b} \frac{1+i_{t-1}}{1+\pi_{t}} b_{t}-\phi_{x} x_{t} \\
u^{\prime}\left(c_{t}^{P}\right) & =\beta E_{t} \frac{1+i_{t}}{1+\pi_{t+1}} u^{\prime}\left(c_{t+1}^{P}\right) .
\end{aligned}
$$

\section{B.5 Welfare function and second-order approximation}

The second-order approximation technique used is described in detail in Woodford (2003, Chapter 6) and Benigno and Woodford $(2005,2012)$ for RANK and in Bilbiie $(2008,2018)$ for TANK. A second-order approximation of $\mathrm{P}$ agents' utility delivers:

$$
\begin{aligned}
U_{t}^{P}-U^{P} & =U_{c}^{P} c^{P}\left(\hat{c}_{t}^{P}+\frac{1-\gamma}{2}\left(\hat{c}_{t}^{P}\right)^{2}\right)+U_{L}^{P} l^{P}\left(\hat{l}_{t}^{P}+\frac{1+\varphi}{2}\left(\hat{l}_{t}^{P}\right)^{2}\right) \\
& =\left(c^{P}\right)^{1-\gamma}\left(\hat{c}_{t}^{P}+\frac{1-\gamma}{2}\left(\hat{c}_{t}^{P}\right)^{2}-\frac{l^{P}}{c^{P}}\left(\hat{l}_{t}^{P}+\frac{1+\varphi}{2}\left(\hat{l}_{t}^{P}\right)^{2}\right)\right)
\end{aligned}
$$

where the second equality used SS under subsidy $w=1, U_{L}^{P}=-U_{C}^{P}$

For $\mathrm{N}$ agents:

$$
U_{t}^{N}-U^{N}=\left(c^{N}\right)^{1-\gamma}\left(\hat{c}_{t}^{N}+\frac{1-\gamma}{2}\left(\hat{c}_{t}^{N}\right)^{2}\right)
$$

Aggregating:

$$
\begin{aligned}
U_{t}-U & =\left(c^{P}\right)^{-\gamma}\left(n c^{P} \hat{c}_{t}^{P}-n l^{P} \hat{l}_{t}^{P}+\left(\frac{c^{N}}{c^{P}}\right)^{-\gamma}(1-n) c^{N} \hat{c}_{t}^{N}\right) \\
& +n\left(c^{P}\right)^{1-\gamma}\left(\frac{1-\gamma}{2}\left(\hat{c}_{t}^{P}\right)^{2}-\frac{l^{P}}{c^{P}} \frac{1+\varphi}{2}\left(\hat{l}_{t}^{P}\right)^{2}\right)+(1-n)\left(c^{N}\right)^{1-\gamma} \frac{1-\gamma}{2}\left(\hat{c}_{t}^{N}\right)^{2}
\end{aligned}
$$


Economy Resource Constraint 2nd order approx

$$
\begin{aligned}
& (1-n) c_{t}^{N}+n c_{t}^{P} \\
\simeq & n c^{P} \hat{c}_{t}^{P}+(1-n) c^{N} \hat{c}_{t}^{N}+\frac{1}{2}\left((1-n) c^{N}\left(\hat{c}_{t}^{N}\right)^{2}+n c^{P}\left(\hat{c}_{t}^{P}\right)^{2}\right) \\
= & \left((1-n) \delta+n l_{t}^{P}\right)\left(1-\frac{\psi}{2} \pi_{t}^{2}\right) \\
\simeq & n l^{P} \hat{l}_{t}^{P}+\frac{1}{2} n l^{P}\left(\hat{l}_{t}^{P}\right)^{2}-\frac{\psi \pi}{1-\frac{\psi}{2} \pi^{2}} \pi_{t}-\frac{1}{2} \frac{\psi}{1-\frac{\psi}{2} \pi^{2}} \pi_{t}^{2} \\
= & n l^{P} \hat{l}_{t}^{P}+\frac{1}{2} n l^{P}\left(\hat{l}_{t}^{P}\right)^{2}+\hat{\Delta}_{t} \\
\hat{\Delta}_{t}= & -\frac{\nu \pi}{1-\frac{\nu}{2} \pi^{2}} \pi_{t}-\frac{1}{2} \frac{\nu}{1-\frac{\nu}{2} \pi^{2}} \pi_{t}^{2}
\end{aligned}
$$

Use in approx $\mathrm{U}$

$$
\begin{gathered}
U_{t}-U=\left(c^{P}\right)^{-\gamma}\left(\begin{array}{c}
n c^{P} \hat{c}_{t}^{P}-n l^{P} \hat{l}_{t}^{P}+\left(\frac{c^{N}}{c^{P}}\right)^{-\gamma}(1-n) c^{N} \hat{c}_{t}^{N}+n c^{P} \frac{1-\gamma}{2}\left(\hat{c}_{t}^{P}\right)^{2}-n c^{P} \frac{l^{P}}{c^{P}} \frac{1+\varphi}{2}\left(\hat{l}_{t}^{P}\right)^{2} \\
+(1-n)\left(\frac{c^{N}}{c^{P}}\right)^{-\gamma} \frac{1-\gamma}{2} c^{N}\left(\hat{c}_{t}^{N}\right)^{2}
\end{array}\right) \\
=\left(c^{P}\right)^{-\gamma}\left(\begin{array}{c}
n c^{P} \hat{c}_{t}^{P}+(1-n) c^{N} \hat{c}_{t}^{N}+\frac{1}{2}\left((1-n) c^{N}\left(\hat{c}_{t}^{N}\right)^{2}+n c^{P}\left(\hat{c}_{t}^{P}\right)^{2}\right) \\
-n l^{P} \hat{l}_{t}^{P}-\frac{1}{2} n l^{P}\left(\hat{l}_{t}^{P}\right)^{2} \\
+(1-n)\left(\left(\frac{c^{N}}{c^{P}}\right)^{-\gamma}-1\right) c^{N}\left(\hat{c}_{t}^{N}+\frac{1}{2}\left(\hat{c}_{t}^{N}\right)^{2}\right) \\
-\frac{\gamma}{2} n c^{P}\left(\hat{c}_{t}^{P}\right)^{2}-n l^{P} \frac{\varphi}{2}\left(\hat{l}_{t}^{P}\right)^{2} \\
-\frac{\gamma}{2}(1-n)\left(\frac{c^{N}}{c^{P}}\right)^{-\gamma} c^{N}\left(\hat{c}_{t}^{N}\right)^{2}
\end{array}\right)
\end{gathered}
$$

The first two lines are equal to delta from the ERC approx, and use inequality notation $q^{\gamma}=$ $1+\frac{(1+\pi) \beta^{-1}-1}{1-\alpha}$

$$
=\left(c^{P}\right)^{-\gamma}\left(\begin{array}{c}
\hat{\Delta}_{t} \\
+(1-n)\left(q^{\gamma}-1\right) c^{N}\left(\hat{c}_{t}^{N}+\frac{1}{2}\left(\hat{c}_{t}^{N}\right)^{2}\right) \\
-\frac{\gamma}{2} n c^{P}\left(\hat{c}_{t}^{P}\right)^{2}-n l^{P} \frac{\varphi}{2}\left(\hat{l}_{t}^{P}\right)^{2} \\
-\frac{\gamma}{2}(1-n) q^{\gamma} c^{N}\left(\hat{c}_{t}^{N}\right)^{2}
\end{array}\right)
$$

Recall that at the Friedman rule this is unity, and the linear term drops out. Otherwise, it is larger than 1 and the linear term has a positive coefficient - increasing the consumption of $\mathrm{N}$ closes the inequality gap, providing a first-order benefit.

The quadratic term is (ignoring price dispersion because in quadratic terms it becomes third or fourth order and using $\left.n l^{P} \frac{\varphi}{2}\left(\hat{l}_{t}^{P}\right)^{2}=\frac{\varphi / 2}{1-(1-n) \delta_{c}} \hat{c}_{t}^{2}\right)$ :

$$
-\frac{\left(c^{P}\right)^{-\gamma} c}{2}\left(\gamma\left(n p\left(\hat{c}_{t}^{P}\right)^{2}+(1-n) h q^{\gamma}\left(\hat{c}_{t}^{N}\right)^{2}\right)+\frac{\varphi}{1-(1-n) \delta_{c}} \hat{c}_{t}^{2}\right)
$$


Now use

and inequality is $\mathrm{P}$

$$
\left(c_{t}^{P}\right)^{2}=\left(\frac{1}{n p}\right)^{2} \hat{c}_{t}^{2}-2 \frac{(1-n) h}{(n p)^{2}} \hat{c}_{t}^{N} c_{t}+\left(\frac{(1-n) h}{n p}\right)^{2}\left(\hat{c}_{t}^{N}\right)^{2}
$$

$$
\begin{gathered}
Q_{t}=\frac{C^{P}}{C^{N}} \\
q_{t}=\frac{1}{n p}\left(c_{t}-c_{t}^{N}\right)
\end{gathered}
$$

Express sum of squared consumptions as

$$
\begin{aligned}
& n p\left(\hat{c}_{t}^{P}\right)^{2}+(1-n) h q^{\gamma}\left(\hat{c}_{t}^{N}\right)^{2} \\
= & \frac{1}{n p} \hat{c}_{t}^{2}-2 \frac{(1-n) h}{n p} \hat{c}_{t}^{N} c_{t}+\frac{((1-n) h)^{2}}{n p}\left(\hat{c}_{t}^{N}\right)^{2}+(1-n) h q^{\gamma}\left(\hat{c}_{t}^{N}\right)^{2} \\
= & \hat{c}_{t}^{2}+\frac{(1-n) h}{n p}\left(\hat{c}_{t}^{2}-2 \hat{c}_{t}^{N} c_{t}+\left(\hat{c}_{t}^{N}\right)^{2}-\left(\hat{c}_{t}^{N}\right)^{2}+(1-n) h\left(\hat{c}_{t}^{N}\right)^{2}+n p q^{\gamma}\left(\hat{c}_{t}^{N}\right)^{2}\right) \\
= & \hat{c}_{t}^{2}+\frac{(1-n) h}{n p}\left(\left(\hat{c}_{t}-\hat{c}_{t}^{N}\right)^{2}+n p\left(q^{\gamma}-1\right)\left(\hat{c}_{t}^{N}\right)^{2}\right) \\
= & \hat{c}_{t}^{2}+n p(1-n) h \hat{q}_{t}^{2}+(1-n) h\left(q^{\gamma}-1\right)\left(\hat{c}_{t}^{N}\right)^{2}
\end{aligned}
$$

Thus the loss function becomes, rearranging and ignoring terms independent of policy:

$$
\begin{aligned}
=-\left(c^{P}\right)^{-\gamma} c\left(\begin{array}{c}
-\hat{\Delta}_{t}-(1-n)\left(q^{\gamma}-1\right) h\left(\hat{c}_{t}^{N}+\frac{1}{2}\left(\hat{c}_{t}^{N}\right)^{2}\right) \\
\gamma\left(n p\left(\hat{c}_{t}^{P}\right)^{2}+(1-n) h q^{\gamma}\left(\hat{c}_{t}^{N}\right)^{2}\right)+\frac{\varphi}{1-(1-n) \delta_{c}} \hat{c}_{t}^{2}
\end{array}\right) \\
=-\left(c^{P}\right)^{-\gamma} c\left(\begin{array}{c}
\left(\gamma+\frac{\varphi}{1-(1-n) \delta_{c}}\right) \hat{c}_{t}^{2}-\hat{\Delta}_{t} \\
-(1-n)\left(q^{\gamma}-1\right) h\left(\hat{c}_{t}^{N}+\frac{1-\gamma}{2}\left(\hat{c}_{t}^{N}\right)^{2}\right) \\
+\gamma n p(1-n) h \hat{q}_{t}^{2}
\end{array}\right) \\
\mathcal{L}=\left(c^{P}\right)^{-\gamma} c\left(\begin{array}{c}
-\hat{\Delta}_{t}-\left(q^{\gamma}-1\right)(1-n) h\left(\hat{c}_{t}^{N}+\frac{1}{2}\left(\hat{c}_{t}^{N}\right)^{2}\right) \\
+\frac{\gamma-1}{2}\left(n p\left(\hat{c}_{t}^{P}\right)^{2}+(1-n) h q^{\gamma}\left(\hat{c}_{t}^{N}\right)^{2}\right)+\frac{1+\varphi}{2} \frac{1}{1-(1-n) \delta_{c}} \hat{c}_{t}^{2}
\end{array}\right) \\
=-\left(c^{P}\right)^{-\gamma} c\left(\begin{array}{c}
\hat{\Delta}_{t}+\left(q^{\gamma}-1\right)(1-n) h\left(\hat{c}_{t}^{N}+\frac{1}{2}\left(\hat{c}_{t}^{N}\right)^{2}\right) \\
+\frac{\gamma}{2} n p(1-n) h \hat{q}_{t}^{2}+\left(\frac{\varphi}{2} \frac{1}{1-(1-n) \delta_{c}}+\frac{\gamma}{2}\right) \hat{c}_{t}^{2}
\end{array}\right)
\end{aligned}
$$

Adding and subtracting the steady-state inflation constant and ignoring all terms independent of policy, we obtain the loss function

$$
\frac{1}{2} E_{0} \sum_{t=0}^{\infty} \beta^{t}\left\{\begin{array}{c}
\frac{\nu}{1-\frac{\nu}{2} \pi^{2}} \tilde{\pi}_{t}^{2}+\left(\gamma+\frac{\varphi}{1-(1-n) \delta_{c}}\right) \hat{c}_{t}^{2} \\
+\gamma n p(1-n) h \hat{q}_{t}^{2}-\Lambda\left[\hat{c}_{t}^{N}+\frac{1-\gamma}{2}\left(\hat{c}_{t}^{N}\right)^{2}\right]
\end{array}\right\}
$$

where the optimal relative weight on the linear term is $\Lambda=2(1-n) h\left(q^{\gamma}-1\right)$. The new relevant terms are $\gamma n p(1-n) h \hat{q}_{t}^{2}$, which captures the welfare cost of the volatility of inequality (naturally, this drops out if all agents are identical, $n=0$ or $n=1$ ); and the last term discussed at length intext (of which the second, quadratic part is just a risk correction). 


\section{B.6 "New Keynesian cross" model with endogenous $\mathrm{N}$ income}

We refer the interested reader to Bilbiie $(2008,2018,2019)$ for more details; here, we outline the equations that change relative to our baseline model with exogenous income of $\mathrm{N}$. In this model, $\mathrm{N}$ agents work and receive the same market real wage as $\mathrm{P}$ agents. For simplicity and to isolate our channel of insurance through liquidity (rather than different hours worked), we further assume that hours worked are pooled by a union and labor is demand-determined - thus following Galí et al, 2007 (see also Ascari et al, 2016 for a setup with a union and sticky wages). The equilibrium implication is that hours worked by each agent are identical (and hence equal to the aggregate, since total mass is 1$)$ :

$$
l_{t}^{N}=l_{t}^{P}=l_{t},
$$

and determined by an aggregate hours schedule that we specify as:

$$
w_{t}=\chi\left(l_{t}\right)^{\varphi}\left(c_{t}\right)^{\gamma}
$$

Since $l_{t}$ now replaces $\delta$ in the expression for utility of $N$, aggregate welfare will be $n u\left(c_{t}^{P}\right)+$ $(1-n) u\left(c_{t}^{N}\right)-\frac{\chi}{1+\varphi} l_{t}^{1+\varphi}$. The budget constraint for $\mathrm{N}$ agents is thus (having imposed asset market clearing and equilibrium, in particular for money)

$$
c_{t}^{N}=w_{t} l_{t}-\tau_{t}+\frac{1-\alpha}{1-n} \frac{m_{t}^{t o t}}{1+\pi_{t}}-T_{t}^{N}
$$

where $\tau_{t}$ are as before monetary transfers and $T_{t}^{N}$ are taxes used to pay for the sales subsidy given to firms. As in the benchmark, firms' profits are

$$
d_{t}=\left(1+\sigma-\frac{w_{t}}{A_{t}}-\frac{\nu}{2} \pi_{t}^{2}\right) Y_{t}
$$

where total production is now $Y_{t}=A_{t} l_{t}$. Assuming that the entire subsidy is financed via taxes levied on consumers every period, we specify a process for the distribution of taxes as:

$$
T_{t}^{N}=\frac{\theta}{1-n} \sigma Y_{t}
$$

where $\theta$ is thus the share of the subsidy to firms levied on $N$ households. The economy resource constraint is $c_{t}=\left(1-\frac{\nu}{2} \pi_{t}^{2}\right) Y_{t}$.

Assuming and optimal subsidy $\sigma=(\varepsilon-1)^{-1}$ and $\theta=0$ (our implicit assumption in the baseline model with exogenous $\mathrm{N}$ income) is no longer possible, because the assumption of endogenous labor would then imply perfect insurance in steady-state $\left(w=1 \rightarrow c^{N}=l=c=c^{P}\right)$. This, in turn, implies a cashless equilibrium as there is no reason to hold money. We therefore assume for this part that there is no implicit fiscal redistribution associated with the supply-side policy: $\theta=1-n$ implying that taxes are uniform $T_{t}^{N}=T_{t}^{P}=T_{t}=\sigma Y_{t}$. We contrast this with the "distorted SS" case where $\sigma=0$. 
As for the quadratic approximation to the aggregate welfare function, the main difference is as follows. Utility of $\mathrm{P}$ is unchanged, but utility of $\mathrm{N}$ becomes

$$
U_{t}^{N}-U^{N}=\left(c^{N}\right)^{1-\gamma}\left(c_{t}^{N}+\frac{1-\gamma}{2}\left(c_{t}^{N}\right)^{2}-\frac{l^{N}}{c^{N}}\left(l_{t}^{N}+\frac{1+\varphi}{2}\left(l_{t}^{N}\right)^{2}\right)\right)
$$

Aggregating as before and imposing the symmetric labor choice in steady state it can be easily shown that the linear term boils down to

$$
\left(c^{P}\right)^{-\gamma} c\left(-\Delta_{t}+\left(q^{\gamma}-1\right)(1-n)\left(h c_{t}^{N}-l_{t}^{N}\right)\right)
$$

which for our model with equal hours across agents is $\left(c^{P}\right)^{-\gamma} c\left(-\Delta_{t}+\left(q^{\gamma}-1\right)(1-n)\left(h c_{t}^{N}-l_{t}\right)\right)$. The quadratic term is different from the previous only in that the weight on consumption/output volatility is $\Lambda_{c}=\varphi+\gamma$. (this part is identical to Bilbiie, 2008-but that paper focuses on a steadystate with $q=1$ ). Notice that the expression for $q$ that governs the liquidity-insurance motive (or distortion) is as before-because the self-insurance equation still holds-but in order to determine optimal long-run inflation and the consumption share of $\mathrm{N}$ we have now (because $w l=c$ ):

$$
h=\frac{c^{N}}{c}=\frac{w l}{c}+\left(\pi+\frac{1-\alpha}{1-n}\right) \frac{1}{1+\pi} \frac{m}{c}-\frac{T^{N}}{c}=\frac{(1+\sigma) \frac{\varepsilon-1}{\varepsilon}-\frac{\theta}{1-n} \sigma}{1-\frac{\nu}{2} \pi^{2}}+\left(\pi+\frac{1-\alpha}{1-n}\right) \frac{\mu}{1+\pi}
$$

